\title{
Critical Risk Indicators (CRIs) for the electric power grid: a survey and discussion of interconnected effects
}

\author{
Judy P. Che-Castaldo ${ }^{1}$ (i) $\cdot$ Rémi Cousin ${ }^{2}$-Stefani Daryanto ${ }^{3}$. Grace Deng ${ }^{4}$ Mei-Ling E. Feng ${ }^{1} \cdot$ Rajesh K. Gupta $^{5}$. \\ Dezhi Hong ${ }^{5} \cdot$ Ryan M. McGranaghan ${ }^{6}$. Olukunle O. Owolabi ${ }^{7}$. Tianyi Qu ${ }^{8}$. Wei Ren ${ }^{3}$. Toryn L. J. Schafer ${ }^{4}$. \\ Ashutosh Sharma ${ }^{9,10}$. Chaopeng Shen ${ }^{9} \cdot$ Mila Getmansky Sherman ${ }^{8} \cdot$ Deborah A. Sunter $^{7,11,12,13} \cdot$ Bo Tao $^{3}$. \\ Lan Wang $^{14}$. David S. Matteson ${ }^{4}$
}

Accepted: 5 June 2021 / Published online: 17 July 2021

(c) The Author(s), under exclusive licence to Springer Science+Business Media, LLC, part of Springer Nature 2021

\begin{abstract}
The electric power grid is a critical societal resource connecting multiple infrastructural domains such as agriculture, transportation, and manufacturing. The electrical grid as an infrastructure is shaped by human activity and public policy in terms of demand and supply requirements. Further, the grid is subject to changes and stresses due to diverse factors including solar weather, climate, hydrology, and ecology. The emerging interconnected and complex network dependencies make such interactions increasingly dynamic, posing novel risks, and presenting new challenges to manage the coupled human-natural system. This paper provides a survey of models and methods that seek to explore the significant interconnected impact of the electric power grid and interdependent domains. We also provide relevant critical risk indicators (CRIs) across diverse domains that may be used to assess risks to electric grid reliability, including climate, ecology, hydrology, finance, space weather, and agriculture. We discuss the convergence of indicators from individual domains to explore possible systemic risk, i.e., holistic risk arising from cross-domain interconnections. Further, we propose a compositional approach to risk assessment that incorporates diverse domain expertise and information, data science, and computer science to identify domain-specific CRIs and their union in systemic risk indicators. Our study provides an important first step towards datadriven analysis and predictive modeling of risks in interconnected human-natural systems.
\end{abstract}

Keywords Critical risk indicator $\cdot$ Electric power grid $\cdot$ Risk $\cdot$ Multi-disciplinary $\cdot$ Uncertainty $\cdot$ Systemic risk

Judy P. Che-Castaldo

jchecastaldo@lpzoo.org

1 Conservation \& Science Department, Lincoln Park Zoo, 2001 N. Clark St. Chicago, Chicago, IL, USA

2 International Research Institute for Climate and Society, Earth Institute/Columbia University, New York, USA

3 Department of Plant and Soil Sciences, College of Agriculture, Food and Environment, University of Kentucky, Lexington, USA

4 Department of Statistics and Data Science, Cornell University, New York, USA

5 Halicioglu Data Science Institute and Department of Computer Science \& Engineering, University of California, San Diego, CA, USA

6 Atmospheric and Space Technology Research Associates, Louisville, CO, USA

7 Department of Civil and Environmental Engineering, Tufts University, Medford, MA, USA
8 Department of Finance, Isenberg School of Management, UMASS Amherst, Amherst, MA, USA

9 Civil and Environmental Engineering, Pennsylvania State University, State College, PA, USA

10 Department of Hydrology, Indian Institute of Technology Roorkee, Roorkee, India

11 Department of Mechanical Engineering, Tufts University, Medford, MA, USA

12 Tufts Institute of the Environment, Tufts University, Medford, MA, USA

13 Center for International Environment and Resource Policy at The Fletcher School, Tufts University, Medford, MA, USA

14 Department of Management Science, Miami Herbert Business School, University of Miami, Coral Gables, FL, USA 


\section{Introduction}

The electrical power grid is an example of an emerging class of human-natural systems that involve complex interdependent processes to carry out their primary functions. With the emergence of pervasive connectivity through computer/communication networks and cloud computing, these interactions are increasingly dynamic, representing myriad environmental changes and human activities. For instance, abnormal climate leads to changes in hydrology which can influence the inputs to hydroelectric production (Uría-Martínez et al. 2021; Voisin et al. 2016; Scott 2013). Similarly, space weather is a well-known source of disturbance to the power grid (Boteler 2013), while wildlife can impact its reliability (Doostan and Chowdhury 2019; Polat et al. 2016; NRECA 2016; Maliszewski et al. 2012; Chow and Taylor 1995). Agricultural production (Lewis and Severnini 2020; Hicks 2014), water access, distribution, and groundwater pumping (Zablocki 2019) serve on the demand side of the grid (Gonzalez et al. 2020). In turn, the thermal power plants are large water users and, in unfortunate events, could pose threats of various forms to ecosystems (Marques et al. 2019; Falke et al. 2011).

Many of these subsystems are shifting due to the stresses of climate change as well as integration of renewable energy sources and electric vehicles causing large variability in electricity use and availability. The hydrologic cycle is undergoing intensification with more frequent floods and droughts. Droughts, in particular, increase the propensity for wildfires which directly negatively impact the power grid through power supply interruptions and physical destruction of the grid (Allen-Dumas et al. 2019; Dian et al. 2019). On the other hand, droughts can decrease hydropower (Gleick 2015) and are known to lead to fluctuations in water and food commodity prices (Badiani-Magnusson and Jessoe 2018). Given the increasing variability of and stress on these subsystems, there is an ever-increasing need to understand risks from a holistic point of view. We can use quantifiable risk measures to design strategies to improve resilience of the electric grid during periods of vulnerability.

Several concepts seek to characterize a system's functional response during periods of vulnerability, describing how the system minimizes losses, how it maintains desired functions, and its rate of recovery (Galaitsi et al. 2020). Vulnerability can be defined as the problems a system faces to maintain its function after an accumulation of risk leads to an unwanted event (Sperstad et al. 2019). These vulnerabilities can be a result of the interdependencies between system components, each with its own sets of risk that can compound into systemic risks (Hynes et al. 2020; Golan et al. 2020). Systemic risk involves a system, e.g., a collection of interconnected domains, through which losses, insolvency, and natural disasters can quickly propagate resulting in systemic distress (Billio et al. 2012). These interdependencies between diverse components in a system can provide profound insights into the health and risk states of the system as a whole, yet there is a dearth of rigorous definition, understanding, and meaningful review of existing indicators of risk for society's most important systems (Galaitsi et al. 2020; Golan et al. 2020; Brand and Jax 2007; Raoufi et al. 2020; Izadi et al. 2021). Additionally, despite a recent surge in studies of intra-system resiliency, there is still a gap in studies of inter-system networks across interdependent sectors (Golan et al. 2020; Buldyrev et al. 2010).

In this paper, we fill the gap with a survey of risk indicators for the electric power grid system, identifying those indicators across a range of domains that must be considered to improve the resiliency of the power grid. Definitions of 'resiliency' often overlap with other terms that characterize systemic functional responses (Raoufi et al. 2020; Galaitsi et al. 2020; Brand and Jax 2007; Maliszewski et al. 2012; Akhgarzarandy et al. 2021; Izadi et al. 2021). Resiliency encompasses multiple components that describe the system's reaction, response to, and recovery from disturbance (Raoufi et al. 2020; Voropai 2020; Stankovic 2018). In this survey, we concentrate on the reactive components of power system resilience (following Raoufi et al. 2020) by focusing on the electric grid system's ability to withstand low-frequency, high-impact disasters efficiently while minimizing interruption in electricity supply. Resiliency emphasizes the addition of risk from acute events and builds upon system reliability which focuses on inherent risk from recurring events (Akhgarzarandy et al. 2021; Izadi et al. 2021; Stankovic 2018; Ciapessoni et al. 2019; Jufri et al. 2019; Sperstad et al. 2019).

Previous literature has demonstrated the importance of studying interdependencies of critical infrastructure, which are the frameworks underlying complex, adaptive systems that provide institutional services essential for the economy, government, and society as a whole (Rinaldi et al. 2002). Although managers of critical infrastructure have taken approaches to prepare for frequent and predictable disturbances, termed as chronic threats (Galaitsi et al. 2020), they still lack the capacity to account for and recover from extreme events with low probabilities of occurrence (Kurth et al. 2020). Following one definition of risk from the Society of Risk Analysis (Aven et al. 2018), we define risk as the potential for realization of unwanted, negative consequences of an event. We take a rigorous approach to risk measurement, defining the term Critical Risk Indicator (CRI) as quantifiable information specifically associated with an unfavorable state, which may be a disastrous activity (cumulative) or a catastrophic event (acute; Galaitsi et al. 
2020) that is devastating and leads to ruinous losses. We take a power supply interruption in the power grid as the realization of risk in the context for CRI development in this study. Our subsequent CRIs can be used to quantify risks that can overwhelm the coping capacity of the energy system (Sperstad et al. 2019; Abedi et al. 2018; Zio 2016) leading to undesirable emergent behaviors (Rinaldi et al. 2002) and critical, wide-spread, multi-domain vulnerability. With a more complete understanding of the full inter-system network, grid managers can better prepare for, anticipate, and detect a more holistic range of potential risks to the electrical grid and as a result, sustain critical operations and speed up its recovery in the face of future extreme events (Ciapessoni et al. 2019).

This paper goes beyond surveying traditional risk indicators used in the electric energy sector and captures the risk indicators across diverse domains. We broaden the interdependencies of human-centered critical infrastructure to the human-natural interface, highlighting the linkages between geophysical and ecological processes, economics, and community services. Specifically, we survey and provide methodologies for critical risk indicators (CRIs) in electric energy, finance, climate, ecology, space weather, hydrology, and agriculture domains. In Sect. 2, we provide an overview of the human-natural domains, discuss how they impact electric power grid resiliency, and present datasets available for developing CRIs in each domain. Section 3 describes the power grid and some existing electric energy CRIs. We conclude in Sect. 4 with a discussion about converging CRIs from individual domains to explore systemic risk. We describe how the human-natural domains are also interdependent, making it necessary to consider systemic risk, or the holistic risk arising from cross-domain interconnections. We borrow the concept of systemic risk and systemic risk measures from finance literature. In finance, systemic risk is the risk that the collapse of one financial institution can lead to the cascade of failures in other financial institutions, and the financial system as a whole (Billio et al. 2012). In our case, measuring systemic risk would capture the health of the interconnected human-natural system and the interdependencies between CRIs in each of the human-natural domains; we refer to the trans-domain systemic risk measures as Systemic Risk Indicators (SRIs). Finally, we propose a compositional approach to develop network-based SRIs by dynamically modeling domain-specific CRIs and quantifying inter-domain connectivity and risk spillovers. Future work will focus on expansion and full implementation of our network approach to measure systemic risk and identify mitigation targets to improve electric power grid resiliency. Although we focus on the electric power grid in the United States, the approach we present here for identifying domain-specific CRIs and their union in SRIs lends itself to broader application for the exploration of the complex

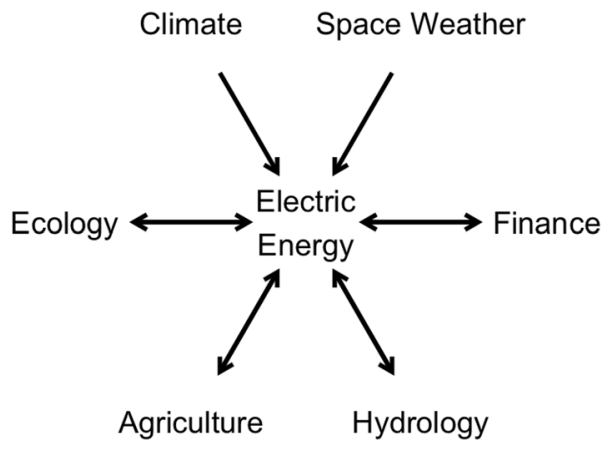

Fig. 1 Nexus of interconnections among different human-natural domains and the electric energy domain

interconnectedness and systemic risks in human-natural systems.

\section{Critical Risk Indicators (CRIs) by domain}

Disruption to the electric power grid is a systemic event which is a result of interdependencies between the following human-natural domains: climate, hydrology, agriculture, ecology, space weather, and finance. Vulnerability in each of the six domains spills over to the electric energy domain, and in some instances the relationship is reversed with electric energy domain vulnerabilities cascading to other human-natural systems. Given that a Critical Risk Indicator (CRI) is an entity that relates to a specific catastrophic outcome, each section will provide an overview of existing CRIs within that particular domain in the context of disruption to the electric power grid. We describe each domain, provide a background on the connection between each domain and risk to the electric power grids, survey top CRIs for each domain that relate to electric power grid, and provide discussion of interconnections with other domains. Table in Section 2.7 summarizes the CRIs. Figure 1 provides a nexus of interconnections among different human-natural domains and the electric energy domain.

\subsection{Climate}

Connection between climate and the electric power grid Climate change and extreme weather (e.g., droughts, Voisin et al., 2016, and strong winds, Wanik et al., 2017) are a leading cause of power supply interruptions. Additionally, climate-related events such as wildfires (Dian et al. 2019) and fallen vegetation can cause up to $90 \%$ of storm-related power interruptions (Wanik et al. 2017). Drought events disrupt not only the electricity supply (e.g., reduced capacity of water-cooled thermoelectric plants (Voisin et al. 2016)) but also storage capacity, as pumped hydropower accounts for 


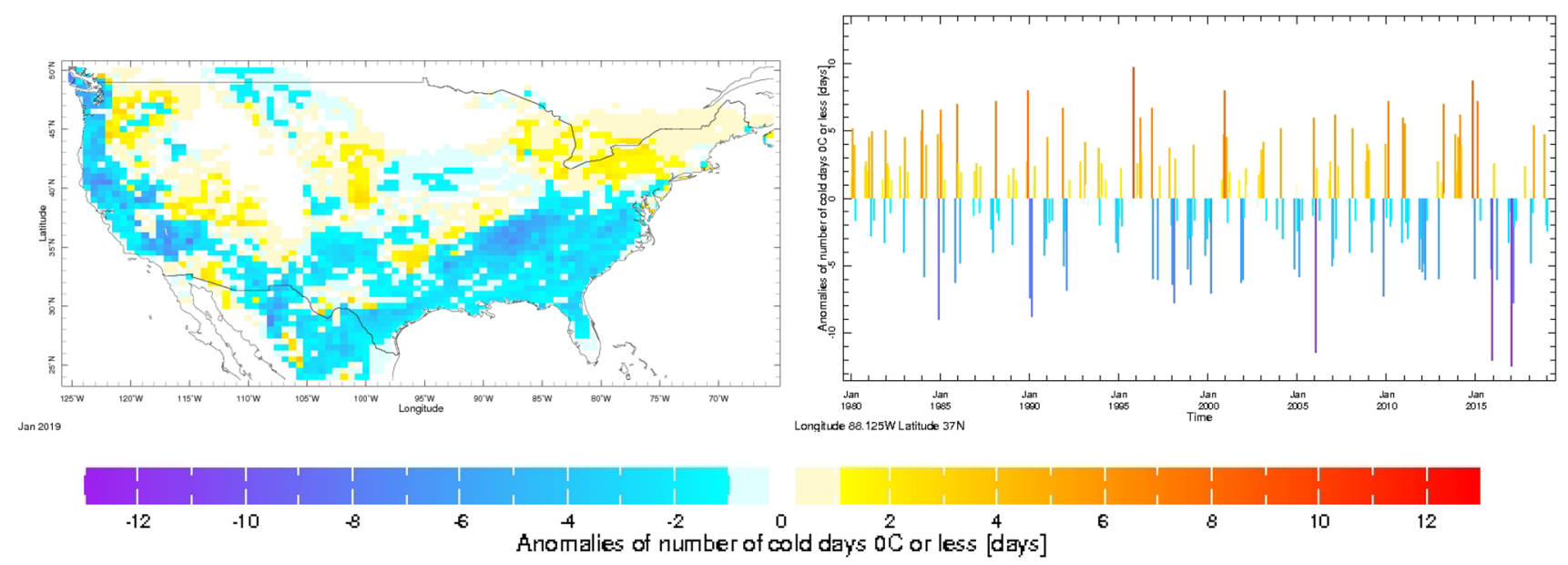

Fig. 2 Number of cold days $\left(0{ }^{\circ} \mathrm{C}\right.$ or less) expressed in anomalies with respect to the 1981-2010 average, from NASA MERRA-2 Reanalysis. For January 2019 (map) and for $88.125^{\circ} \mathrm{W}, 37^{\circ} \mathrm{N}$ (bar plot)

95\% of all utility-scale energy storage in the US (Zablocki 2019). Climate change and extreme weather are also associated with unstable electricity supply from reduced generation from variable renewable energy, such as solar (Feron et al. 2021) and wind (Lin et al. 2012). Heat waves and cold spells are likely to increase power demand to cool and heat buildings. Below freezing temperatures, resulting in ice accumulations, have the potential to damage electric grid infrastructure (Allen-Dumas et al. 2019). Persistent high temperatures led to increased electricity consumption and increased power supply interruptions (California ISO 2021).

Existing CRIs for climate-power grid connections The main objective in climate science is to characterize, understand, and consequently try to predict anomalous climate events. To define what is abnormal, one must first define "normal" conditions. In climate science, these normal conditions are defined as the seasonal cycle, typically defined, given monthly data, as the 30-year average of each month of the year. Then anomalies are simply the departure for a given month and year from that corresponding month average, and thus climate science focuses on yearly time frequencies or lower. This broad concept can take other forms: for instance finer time resolution than the month (e.g., daily, 5-daily, 10-daily); the data can be aggregated at larger time resolution than its step (e.g., monthly 3-month-long season averages, a running average in other words); or anomalies can be standardized or normalized according to different techniques.

In light of this, we consider the following climate domain CRIs that directly relate to the electric power grid:

1. Monthly temperature/precipitation anomalies consist for a given month and year (at any given spatial entity) of the difference between the temperature/precipitation of that month/year with the average over at least 30 years of the temperature/precipitation for that month. High anomalies (negative or positive) would be an indicator of stress towards the power grid. Long-term year-toyear relationship can be assessed between temperature/ precipitation anomalies and power supply interruptions, in particular, when looking at the same time period of the year (e.g., hot summers are known to cause more power supply interruptions than cool ones (California ISO 2021)). But also sequences of adverse conditions from a season to another could be assessed (e.g., cold winters followed by hot summers).

2. Standard Precipitation Index (SPI) is an index used to characterize drought on a range of time scales. It characterizes drought or abnormal wetness at different time scales (Guenang and Kamga 2014). SPI is also related to propensity of wildfires that directly affects power supply interruptions and electric grid infrastructure.

3. Anomalies of number of days a criterion is met (e.g., $>1 \mathrm{~mm} ; \leq 0{ }^{\circ} \mathrm{C}$ ). For example, cooling degree days are summations of positive differences between the daily temperature and a reference base temperature during a season of interest (US Energy Information Administration 2020). For instance summing up, through days, temperature above $20{ }^{\circ} \mathrm{C}$ during the summer, as an indicator of how much cooling power is necessary to maintain desired temperature in buildings. In another example, one could rely on daily data to build monthly anomalies of number of days below a critical temperature (e.g., freezing point, i.e., $0{ }^{\circ} \mathrm{C}$-see Fig. 2) in a month. Such a CRI could be more tailored to relate to power supply interruptions in the winter. 
Available datasets for calculating CRIs There exists a number of datasets of daily or monthly precipitation or temperature, over several decades, that cover the United States, that allow to calculate the CRIs described above. A few examples that we have used or planned on using is as follows. Climatology Lab's gridMET (Abatzoglou 2013) dataset has daily precipitation and temperature data (and more) from 1979 to now and at 1/24th degree of spatial resolution, over the United States. GPCP V2.3 Monthly Analysis Product (Adler et al. 2018) has monthly precipitation from 1979 to now at 2.5 degree spatial resolution, over the globe. The Modern-Era Retrospective Analysis for Research and Applications, Version 2 (MERRA-2) (Gelaro et al. 2017) has daily precipitation and temperature date from 1980 to now at about a half-degree spatial resolution over the globe. The Climate Prediction Center's (CPC) Unified Gauge-Based Analysis of Daily Precipitation over the CONUS (Xie et al. 2007; Chen et al. 2008; Chen and Xie 2008) has daily precipitation data from 1948 to now at a quarter-degree spatial resolution over the CONUS.

\subsection{Hydrology}

Connection between hydrology and electric power grid Hydropower plants generate about $6.7 \%$ of total electricity generation in the United States (US) and account for about $38 \%$ of electricity generation from renewable energy (UríaMartínez et al. 2021). Globally, the percentage of electricity from hydropower is $16 \%$ with this fraction above $90 \%$ in some countries, e.g., Albania, Paraguay, Nepal, Congo, Ethiopia, and Norway (WB 2021). These countries are much more heavily influenced by the natural hydrologic system and annual precipitation. The hydropower production relies on the water available to flow through the turbines that generate electricity. The reservoirs of hydroelectric dams store water that is released through the turbine to produce electricity to meet baseload as well as peak load demands. Thus, hydrology is directly linked to hydropower production through the amount of water flowing into the reservoir and its fluctuations under extreme hydrologic events (e.g., droughts and floods). The outflow from a reservoir is controlled by the reservoir release policies which may be influenced by electricity prices (Gaudard and Romerio 2014; Kanamura and Õhashi 2007). In many other markets, however, the release policies need to consider the variability in supply, along with other factors like ecosystem flow, and could have a large impact on electricity prices (Doorman et al. 2006; Wolfgang et al. 2009). Drought is a hydrologic phenomenon that starts with a period of less precipitation compared to historical normal (meteorological drought), and if precipitation deficit sustains over an extended period, it results in reduced soil moisture (agricultural drought) and surface water (i.e., lakes, reservoirs, rivers, and wetlands) deficit (hydrological drought). Prolonged drought events affect water storage in these reservoirs, and hence limit the ability to generate electricity. The past drought events had substantially impacted the regional/national hydropower productions in different countries. For example, the 2011-2015 California drought resulted in below-average hydropower production that added an economic cost of $\$ 2.0$ billion (Gleick 2015). Further, the fossil fuel-based electricity generation was enhanced to meet the electricity demands in California, leading to a $10 \%$ increase in $\mathrm{CO}_{2}$ emission from power plants (CARB 2015). In Brazil, the 2012-2015 droughts were already causing lowered hydropower productions and elevated thermal dispatches (Zambon et al. 2016).

Existing CRIs for hydrology-power grid connections The hydrologic risk (i.e., potential for hydrological drought) is quantified based on prolonged abnormally low streamflow and groundwater depletion. CRIs in hydrology are (i) the drought indices that quantify the deviation in water availability (surface water or groundwater) compared to longterm historical normal; (ii) multi-month streamflow outlook. Existing CRIs in hydrology include the following:

1. Streamflow Streamflow, when put in historical context, is a useful indicator for hydrologic risks (i.e., potential for drought or flood). The values of streamflow are converted in percentiles and are compared to historical observations during the same period of the year based on a threshold (e.g., 10th \%-ile of past decades distribution). Apart from present streamflow conditions, to provide a useful tool to forecast risk, multi-month streamflow outlook can be estimated based on machine models, of various mechanisms and climate outlooks, e.g., see some preliminary work in Feng et al. (2020), Ouyang et al. (2021) which can be extended to multimonth outlook.

2. Drought indices Several drought indices have been developed over the years to identify droughts and to quantify the drought intensity/severity (Svoboda and Fuchs 2016). Palmer Drought Severity Index (PDSI) and Standardized Precipitation Index (SPI) are the most widely used drought indices. SPI is recommended by the World Meteorological Organization (WMP) and requires only monthly precipitation data. SPI is a meteorological drought index, but it can be computed for multiple time scales (e.g., 3, 6, 12, 24 months) that enable us to examine other types of droughts (agricultural or hydrological). PDSI uses readily available temperature and precipitation data to estimate relative dryness. It is a standardized index that generally spans -10 (dry) to + 10 (wet).

3. Groundwater levels Groundwater depletion rates provide information on excessive pumping activities for irrigation during the drought. The observations of ground- 


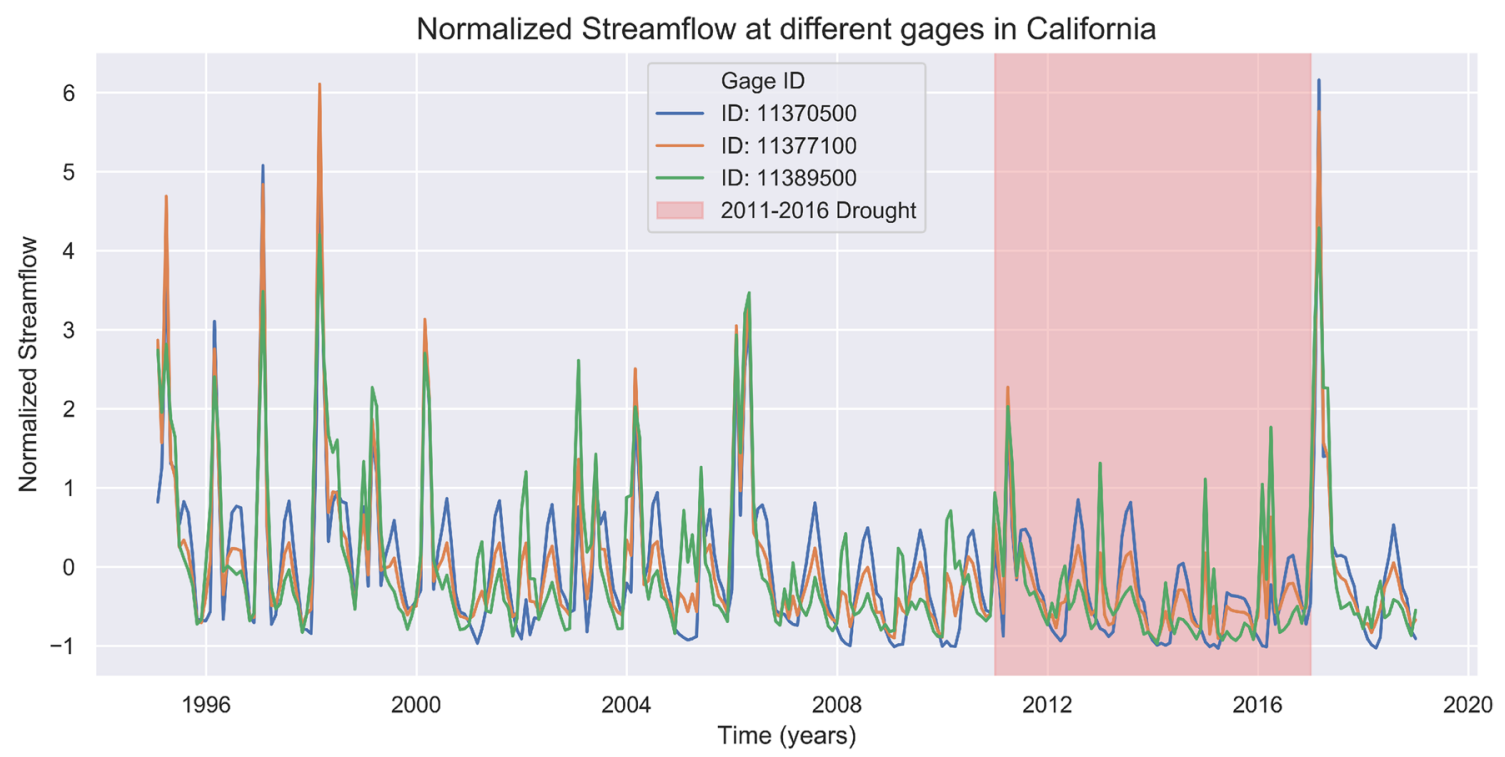

Fig. 3 Time series of normalized streamflow at different gauges in California. The red region highlights streamflow reduction during the 20112016 drought

water wells can be used as a CRI that accounts for the change in groundwater table depth or the fraction of dry wells. The water stored in a region can also be reflected from satellite-based observations of terrestrial water storage (Li et al. 2012; Sun et al. 2012), but the downside of this kind of observations is their very coarse spatio-temporal resolutions. On the other hand, access to groundwater requires energy (Chen et al. 2019; Siddiqi and Jr 2013) and could, in turn, affect the grid.

Available datasets for calculating CRIs: Daily streamflow observations are available for all major rivers in the US from the United States Geological Survey (USGS) National Water Information System (NWIS). ${ }^{1}$ GAGES II (Geospatial Attributes of Gages for Evaluating Streamflow, version II) dataset provides a large set of geospatial data for 9322 gauge sites across the US including environmental features (e.g., climate including historical precipitation, geology, soils, topography) and anthropogenic influences (e.g., land use, road density, presence of dams, canals, or power plants). Figure 3 shows the normalized streamflow for some gauges in California over the period 1995-2019 and highlights the reduction in streamflow during the 2011-2016 drought.

The USGS NWIS provides data on groundwater well observations for sites across US. ${ }^{2}$ Additionally, different states have networks of a large number of monitoring wells. For example, the Department of Water Resources, California

\footnotetext{
$1 \mathrm{https} / / /$ waterdata.usgs.gov/nwis/rt.
}

2 https://waterdata.usgs.gov/nwis/gw. provides groundwater data for thousands of wells in the state on the Water Data Library (WDL). ${ }^{3}$

\subsection{Agriculture}

Connection between agriculture and power grid Many agricultural activities (e.g., pumping for irrigation, supplying water for livestock) benefit from the availability of electricity. Electrification in the rural regions where most agricultural activities occur leads to increases in agricultural production (Lewis and Severnini 2020). Rural electrification is also associated with increased irrigation use in the western region of the US and substantial increases in the average farm size (Lewis and Severnini 2014). Those increases also correspond with advances in power transmission technology, which reduces the constraints on where power plants can be located (Lewis and Severnini 2014). Electricity allows for expansion in agricultural activities through two mechanisms. First, electricity allows mechanization of equipment such as grain mills and electric dryers (Shrestha et al. 2005). Second, electricity allows extended working hours, which again leads to higher production capacity.

Yet, as farm productivity becomes more dependent on grid electricity, it also means that there will be losses if electricity is not available. Security breaches in electric power transmission systems (e.g., outages, transport, etc.) resulted in several blackouts in the US during the late 2000s (Arianos et al. 2009), which incurred large losses in agriculture, particularly when the power disruptions occurred during

3 http://wdl.water.ca.gov/. 


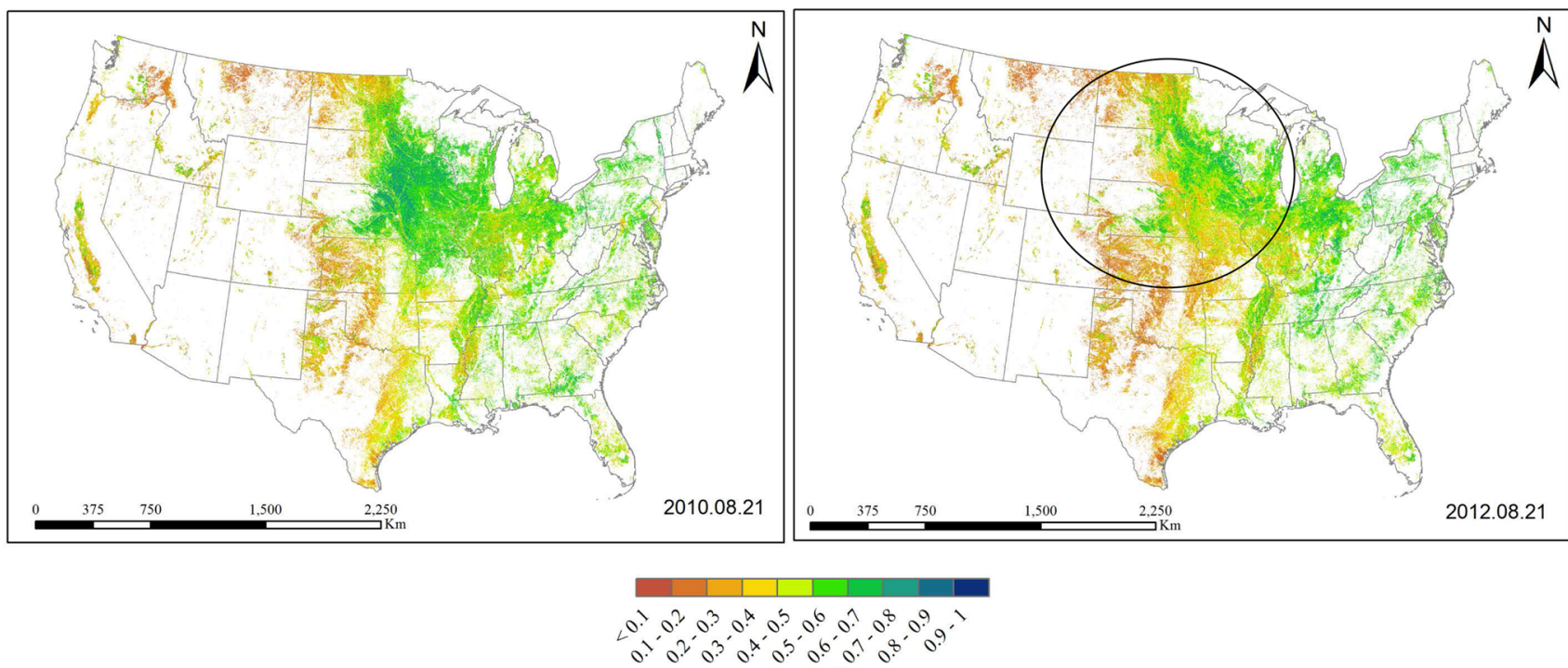

Fig. 4 MODIS EVI values across the US croplands in normal year 2010 (left) and drought year 2012 (right). The two EVI maps were calculated from the MOD09A1 Version 6 product with a 500m spatial resolution and an 8-day temporal resolution

the periods of peak electricity demand (August-September harvest, Lewis and Severnini 2020). A four-hour duration of electricity interruption cost (USD $1.94 \mathrm{~kW}-1$ ) is relatively higher in the agricultural sector compared to coal (USD 0.07 $\mathrm{kW}-1$ ) or metal mining (USD $0.11 \mathrm{~kW}-1$ ) based on 1994 currency value (Badiani-Magnusson and Jessoe 2018). If the food industry, as an extension of agriculture, is included, the interruption cost jumped to USD $50.52 \mathrm{~kW}-1$ due to spoilage (Balducci et al. 2002).

Agriculture acts as both a supplier and a consumer of electricity. As an energy source, the amount of residue generated from agriculture influences electricity supply and generation. In 2016, biomass and waste fuels supplied approximately $2 \%$ of total electricity generation in the US (71.4 billion $\mathrm{kWh}$, Mayes 2017). Wood solids, which come from sources like logging and mill residues, accounted for nearly $33 \%$ the electricity generated from biomass and waste (Mayes 2017). To generate electricity, they can be burned directly in steam-electric power plants or be converted to a gas. The gas then can be burned in steam generators, gas turbines, or internal combustion engine generators (US Department of Energy 2020).

On the other hand, when acting as a consumer of electricity, crop production and cropland area, especially those requiring irrigation, are highly dependent on the steady supply of energy. In 2012, US crop production obtained about $20 \%$ of its energy requirement from electricity (Hicks 2014). The agriculture-heavy regions of Nebraska (i.e., rural south and west) have one of the highest average electricity prices in the state (Brown and Harnish 2014). Demand for irrigation can be costly, because of two main reasons. First, it is expensive to connect dispersed farmlands to the electric grid and second, it is also expensive to provide enough capacity available to meet seasonal irrigation load (Brown and Harnish 2014).

Existing CRIs for agriculture-power grid connections Agriculture risk is related to catastrophic declines in crop biomass production and vegetation index, as well as a possibility of not meeting irrigation demand. The agricultural sector is highly reliant on the electric energy sector, and thus power supply interruptions can exacerbate risk in the agriculture sector. Relevant CRIs for agriculture-power grid connections include the following:

1. Irrigation demand The irrigation demand is a useful indicator for evaluating power grid risk caused by agriculture as a consumer of electricity. The larger irrigation demand requires more energy capacity support, relating to irrigation area and electricity price.

2. Crop biomass production The total biomass production and its reduction are agricultural indicators related to the supply and generation of electricity.

3. Vegetation Index The Enhanced Vegetation Index (EVI) is an 'optimized' vegetation index designed to quantify vegetation greenness (Fig. 4). The EVI represents plant growth status and relates to irrigation demand and final biomass production.

Available datasets for calculating CRIs: Data on the land-use type and irrigated croplands are available from the United States Department of Agriculture, Economic Research Service ${ }^{4}$; https://www.ers.usda.gov/data-produ

\footnotetext{
$\overline{4}$ https://www.ers.usda.gov/data-products/major-land-uses/.
} 


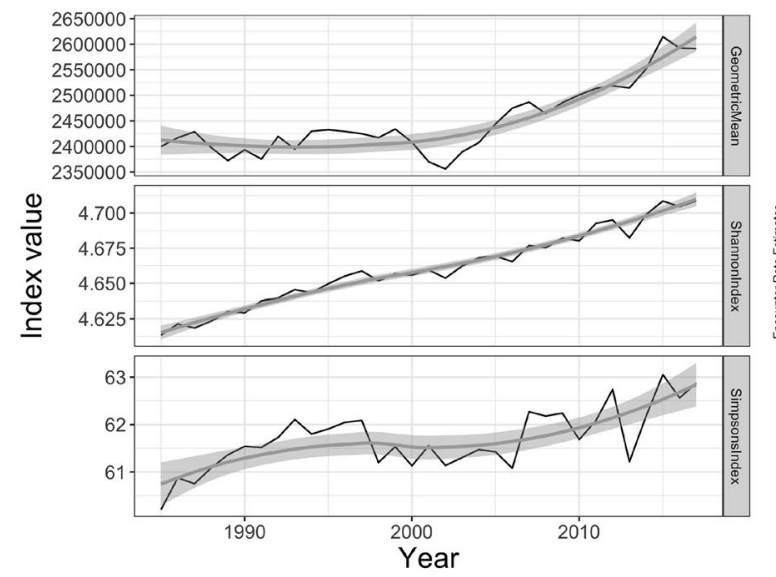

Fig. 5 Ecology CRIs calculated using USGS Breeding Bird Survey annual abundance data for 421 species in North America from 19932017 (left), and monthly estimated relative abundance for the Red-

cts/irrigated-agriculture-in-the-united-states/. Electricity price is available from US Energy Information Administration (note that the agricultural sector is considered as an industrial sector (Brown and Harnish 2014). Electricity power generation from biomass is also available from the US Energy Information Administration. ${ }^{5}$

\subsection{Ecology}

Connection between ecology and the electric power grid Biotic components of the environment can both negatively impact and be impacted by the electrical power grid. Vegetation frequently interferes with overhead power lines, particularly through tree falls, which are more likely to occur during severe weather events (Wanik et al. 2017; Maliszewski et al. 2012). Small mammals and birds cause a large proportion of disruptions to the electricity supply and damage to infrastructure (Chow and Taylor 1995; Doostan and Chowdhury 2019). Negative impacts on wildlife result from coexistence and attraction to electric infrastructure for use as hunting perches, nesting structures, and highways for travel (NRECA 2016). They include electrocutions and collisions with power lines (Polat et al. 2016), and reduction in the quality and amount of species' habitat taken up by electrical grid infrastructure (Marques et al. 2019).

While also accounting for infrastructure design and wildlife protection strategies, the potential for species-power grid interactions depends on both the abundance and distribution of the interacting species. For example, higher densities of individual animals would increase the likelihood for collisions, and power lines located along migration routes

\footnotetext{
5 https://www.eia.gov/electricity/monthly/.
}

bellied Woodpecker (Melanerpes carolinus) in Massachusetts from 2005 to 2018 based on eBird occurrence data (right)

would pose a greater threat to birds than those away from the routes. Although spatial distribution data are available for many taxonomic groups, they typically consist of static maps of species range areas, which may not be useful for detecting associations with catastrophic events in time. In contrast, abundance data are usually time series of repeated counts over time. Moreover, species abundance is directly related to a critical risk in ecology — the risk of biodiversity loss (Brondizio et al. 2019).

Existing CRIs for the ecology-power grid connection The critical risk of biodiversity loss can result from cumulative declines in species abundance, as well as the catastrophic event of species extinction. Potential indicators for the risk of biodiversity loss include direct measures of species abundances, as well as the following:

1. The Living Planet Index (LPI) (Collen et al. 2009) is one of the most comprehensive indicators of global biodiversity status. LPI is calculated as the geometric mean of population abundance trends across all species worldwide with existing abundance time-series data. The geometric mean of relative abundances has empirical (Buckland et al. 2005) and theoretical (Mccarthy et al. 2014) support for being appropriate for assessing the risk of biodiversity loss over time.

2. Community composition metrics are also used to measure change in biodiversity over time (Buckland et al. 2005; Morris et al. 2014). They include species richness (number of species) and metrics of diversity and evenness (e.g., Shannon's or Simpson's index; Fig. 5, left panel).

Available datasets for calculating CRIs Due to the amount of effort and training required, the majority of abundance 
datasets are short term (several years), and collected at single or few sites for single or few species. The USGS Breeding Bird Survey (BBS) is the most extensive existing dataset on animal abundance, with consistent data for a large number of bird species ( 400) and excellent spatial (North America, by state or by Bird Conservation Region) and temporal (annual, 1966-2017) coverage. BBS data are gathered through point count surveys along specified routes using a standardized monitoring protocol, conducted by qualified volunteers. The dataset consists of yearly, species-specific abundance indices estimated from a hierarchical trend model that accounts for differences among routes and observers (Sauer et al. 2017). Raw survey data are also available. A recent study demonstrated the potential of using BBS data for quantifying the magnitude of biodiversity loss (Rosenberg et al. 2019).

Similarly large-scale, consistent abundance datasets do not exist for other species that may interact with the electrical grid, such as squirrels and other small mammals. It may be possible to derive proxies of relative abundance using occurrence datasets such as the Global Biodiversity Information Facility (GBIF). Occurrences differ from abundances because they are sightings or observations of a species at particular locations and times, and therefore are affected by detection probabilities and observer effort in addition to actual species abundances. However, occurrence data have finer spatial and temporal scales and may be more versatile for aligning with other domain data. For example, eBird has occurrence data collected by citizen scientists via semi-structured protocols that can be modeled to account for detection and effort and estimate relative abundance (Strimas-Mackey et al. 2020) (Fig. 5, right panel).

Finally, datasets on the abundance of vegetation that can interact with the electrical grid include the remotely sensed normalized difference vegetation index (NDVI), which is a measure of vegetation cover with resolution of $250 \mathrm{~m}$ and every 16 days. The Soil-Adjusted Vegetation Index (SAVI) is derived from NDVI and was previously used to successfully predict power supply interruptions (Maliszewski et al. 2012).

\subsection{Space weather}

Connection between space weather and the electric power grid During periods of enhanced space weather activity, a series of physical processes beginning with the launch of a coronal mass ejection (CME) or a high-speed stream (HSS) from the Sun gives rise to intense electric currents reaching millions of Amperes surrounding the Earth, which then become electric currents on the ground flowing through electrical transmission lines. This phenomenon, known as Geomagnetically Induced Currents (GICs), can disrupt the operation of high-voltage power grid transformers via overheating and generation of harmonics, potentially leading to failures.
The most fundamental quantity that connects space weather and the electric power grid is the horizontal electric field on the Earth's surface (geoelectric field). The geoelectric field determines the magnitude of GICs that flow on power transmission networks (Boteler 2013; Pirjola 2000). GICs arise from a series of interactions, beginning with the solar cloud of plasma interacting with the Earth's magnetic field, creating currents in space and in the upper atmospheric region known as the ionosphere, which produces the electric field on the ground through magnetic induction. However, knowledge of many aspects of this chain is limited, especially during extreme storms (Ngwira et al. 2015, 2018).

Existing CRIs for space weather-power grid connections In the space weather domain 'critical risk indication' has several potential definitions, including the following:

1. Specification of periods when the Sun is particularly active (proxies: sunspot number, location in the 11-year solar cycle.);

2. Identification of 'geomagnetically effective' periods in solar wind data (Schrijver et al. 2015) (important parameters: magnetic field, particularly the north-south component, velocity, density);

3. Extent of the coupling between the solar wind and the magnetosphere by coupling function proxies: the Borovsky coupling function (Borovsky 2013) and the Newell coupling function (Newell et al. 2007); and

4. Activity of the current systems in the Earth's upper atmosphere proxies: the disturbance storm time index (DST, or Symmetric-H (Sym-H)) (Sugiura et al. 1964), the auroral electrojet index (AE, Davis and Sugiura 1966), and the planetary k-index (Kp, Bartels et al. 1939).

Figure 6 shows a CRI from categories $2-4$ along with direct measurements of GIC (i.e., impact on the power grid). The top panel shows the GIC measurement with a red dashed line indicating a threshold level important to power grid engineers. Vertical orange lines on all plots indicate periods during which the GIC level exceeded the threshold and provide an indication of the behavior of the CRI at those important times. The variables shown are (second panel from the top) the solar wind magnetic field z-component; (third panel from the top) the solar wind velocity; (third panel from the top) the DST/Sym-H index; and (bottom panel) the Newell coupling function.

Given that the currents in the Earth's atmosphere directly drive disturbances to the power grid system, the most relevant category are the proxies of the currents-the geomagnetic indices. These indices are each created by aggregating ground-based magnetometer observations. There are numerous such indices, and we will describe only the most relevant to the power grid application. The most traditional 

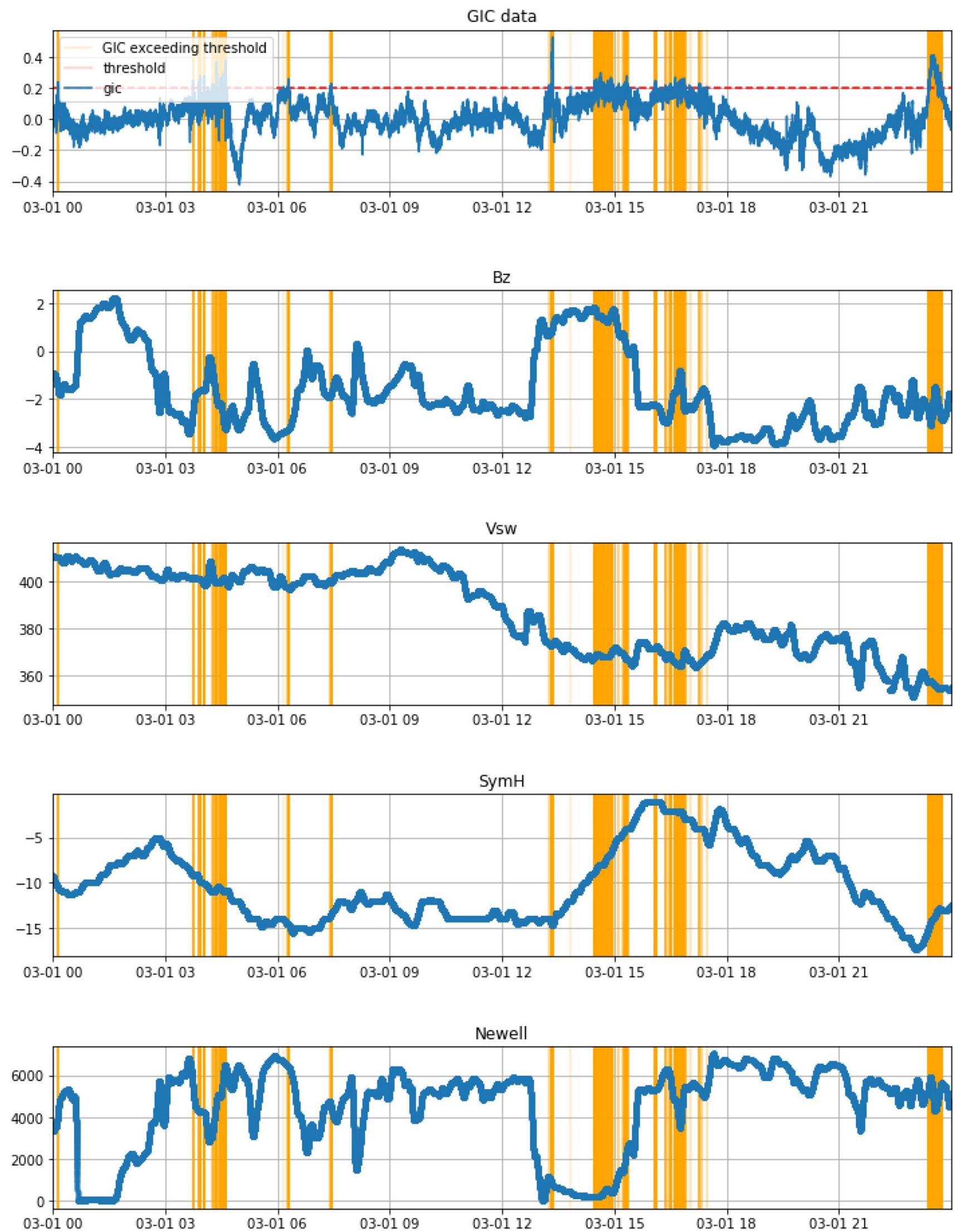
4Fig. 6 Space weather CRIs during a geomagnetic storm on March 1, 2018. The top panel shows the impact on the electric power grid through a direct GIC measurement. The red dashed line indicates a threshold level important to power grid engineers (above which is considered a 'risk.' Vertical orange lines on all plots indicate periods during which the GIC level exceeded the threshold and provide an indication of the behavior of the CRI at those important times. The variables shown are (second panel from the top) the solar wind magnetic field $z$-component; (third panel from the top) the solar wind velocity; (third panel from the top) the DST/Sym-H index; and (bottom panel) the Newell coupling function

data for quantifying potential risk to the power grid by space weather is the planetary k-index (Kp). It has long been used to communicate space weather activity to the power grid. Kp quantifies disturbances in the horizontal component of earth's magnetic field with an integer in the range 0-9 with 1 being calm and 5 or more indicating a geomagnetic storm. It is a single three-hour resolution number for the planet to proxy geomagnetic activity and many power grid models and procedures are queued to it. While Kp has proven useful, it does not provide the level of granularity needed by the power grid community because the risk is different based on region and finer location and on shorter time scales.

Improvement is possible by using more of the information available in ground-based magnetometer measurements. This is the approach of various geomagnetic indices. The DST/Sym-H and AE indices each select a specific set of magnetometers and aggregate their data to provide a more direct indication of the atmospheric currents near the equator $(\mathrm{Sym}-\mathrm{H})$ and the auroral region $(\mathrm{AE})$. These indices are provided on one-minute temporal resolution and give a more regional quantification. The Super Magnetometer Initiative (SuperMAG; https://supermag.jhuapl.edu/ (Gjerloev 2009)) provides their own versions of these indices that uses more magnetometer stations. As mentioned, power grid impacts occur on the regional level, too. Thus, a significant extension of the geomagnetic activity approach is to group magnetometer data by local time region and to create proxies that are regionally dependent. SuperMAG provides these regional indices at one-minute resolution as well.

The state of the art would be direct observations of the power grid disruption, which are regularly collected by utilities, but seldom available for research and predictive model development. The final Space Weather CRIs, therefore, are direct measurements of the induced currents on power grid transformers, GICs. Future CRI development will utilize these data to better quantify the connection between Space Weather variables and power grid risks.

\subsection{Finance}

Connection between finance and the electric power grid Electricity grid and finance are tightly coupled. Fuel costs, generation capacity costs, operating costs, transmissionrelated costs, such as congestion pricing, investments in peak capacity, and costs related to grid infrastructure improvements and maintenance connect the two domains.

Public utility companies such as Pacific Gas Electric, Duke Energy Corp. and others are responsible for being reliable sources of electricity for individuals, private, and public sectors. Public utilities make money from investment in assets such as oil and natural gas pipelines, substations, and transmission lines that are used to provide the service. During financial crises, the finances of public utilities might be constrained due to liquidity and financing constraints, leading to decrease in investments in infrastructure, which increases the susceptibility of infrastructure. The health and longevity of electricity grid is directly impacted by financing and the health of the economy.

Vulnerabilities of the electric grid can also spill over to economy and depress asset values of companies, especially public utility companies. On a macro scale, power supply interruptions directly affect the health of the economy. For large companies, the cost of a power supply interruption can escalate into the millions of dollars per hour of downtime. The US cost of sustained power interruptions is $\$ 44$ billion per year in 2015, which grew by $25 \%$ since 2002 (LaCommare et al. 2018). On a micro scale, power supply interruptions affect the health of companies and can precipitate their default. For example, Southern California Edison agreed to pay $\$ 650,000$ settlement for the 2011 blackout. Due to colossal losses of $\$ 30$ billion during catastrophic wildfires caused by Pacific Gas \& Electric company (PG\&E) equipment that further led to severe power supply interruptions, PG\&E filed for Chapter 11 bankruptcy in 2019.

In addition, energy and finance domains are clearly linked through the costs of commodities, i.e., natural gas, coal, and crude oil, which are standard inputs for electricity generation.

Existing CRIs for finance-power grid connections All measures are constructed using daily data. Volatility Indicator (VIX) is a proxy for financial instability. Public Utility indicator is an index of major US public utility companies. These companies are traded daily on NYSE, major US stock exchange. Futures and spot contracts for crude oil, natural gas, coal, and electricity are traded daily on New York Mercantile Exchange.

\section{Volatility Indicator (VIX)}

The CBOE Volatility Index (VIX) is a measure of expected stock market volatility based on S\&P 500 index options over the next 30 days. It is a measure of implied volatility, and specifically, model-free implied volatility. It is calculated by the Chicago Board Options Exchange (CBOE) and is often termed as the "fear index" or "fear gauge." Market participants use the VIX to measure the 


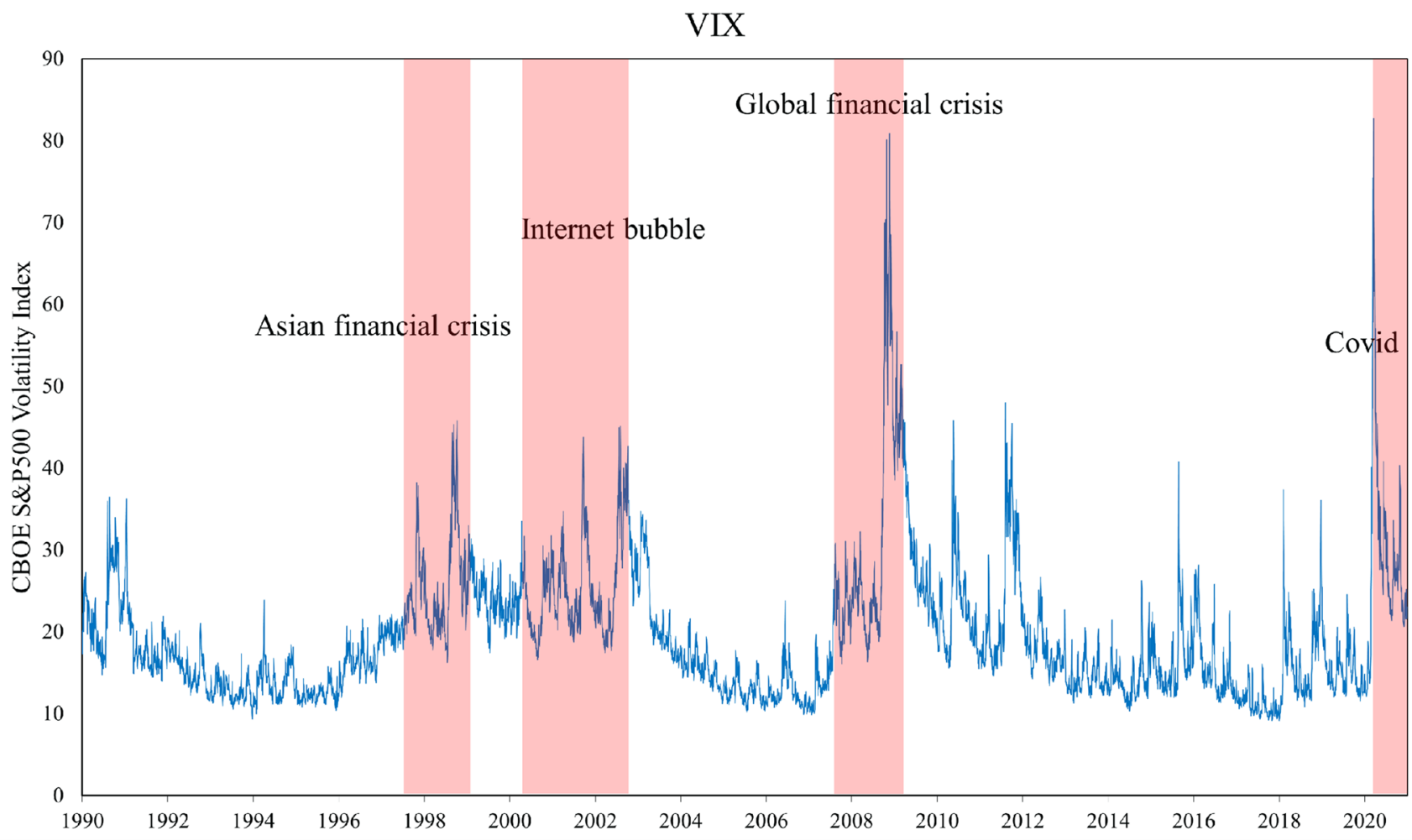

Fig. 7 Daily CBOE S\&P500 Volatility Index (VIX) using closing data from 1/2/1990 to 12/30/2020

level of risk, fear, or stress in the market when making investment decisions.

Mathematically, the VIX is calculated as a 30-day expectation of volatility given by a weighted portfolio of out-of-the-money European options on the S\&P 500 index. The formula is as follows:

$V I X=\sqrt{\frac{2 e^{r \tau}}{\tau}\left(\int_{0}^{F} \frac{P(K)}{K^{2}} d K+\int_{F}^{\infty} \frac{C(K)}{K^{2}} d K\right)}$

where $\tau$ is the number of average days in a month (30 days), $r$ is the risk-free rate, $F$ is the 30-day forward price on the S\&P 500, and $P(K)$ and $C(K)$ are prices for puts and calls with strike $K$ and 30 days to maturity.

While the formula is theoretically complex, the intuition is as follows. It estimates the expected volatility of the S\&P 500 index by aggregating the weighted prices of multiple SPX puts and calls over a wide range of strike prices.

In our data sample of daily CBOE S\&P500 Volatility Index (Fig. 7), VIX ranges from the lowest 9.14 on $11 / 3 / 2017$ to highest 80.86 on $11 / 20 / 2008$. Note, the spike in VIX is associated with financial market turmoil, which happened during the peak of the financial crisis of 2008. VIX also spiked during other financial crises such as the Asian Financial crisis of 1997, the Internet bubble of 2000, and the most recent COVID-19 crisis (March 2020).

\section{Public Utility Indicator}

Public utility company is an organization that maintains the infrastructure for public service. Those companies provide a set of services such as coal, electricity, natural gas, and water.

To construct the critical risk indicator for public utility firms, we collect daily stock prices for five major public utility companies which include Southern California Edison, Pacific Gas \& Electric, Duke Energy Corp, Consolidated Edison, and CMS Energy Corporation. We then calculate daily returns of each company using their daily closing prices and take the equal weighted average of each company's return to construct the aggregate index for public utility firms. This index serves as an indicator of public utility industry and reflects the daily stock performance of major public utility firms.

Figure 8 depicts daily returns for the index of five major public utility companies from $1 / 2 / 1990$ to $12 / 30 / 2020$. The companies are exposed to the state of the economy and had the largest changes in value around Internet bubble and the 2008 financial crisis. Public utility stocks are also exposed to natural disaster risk. Stock price for public utility stocks is directly impacted by natural disasters such as the wildfires in California and 


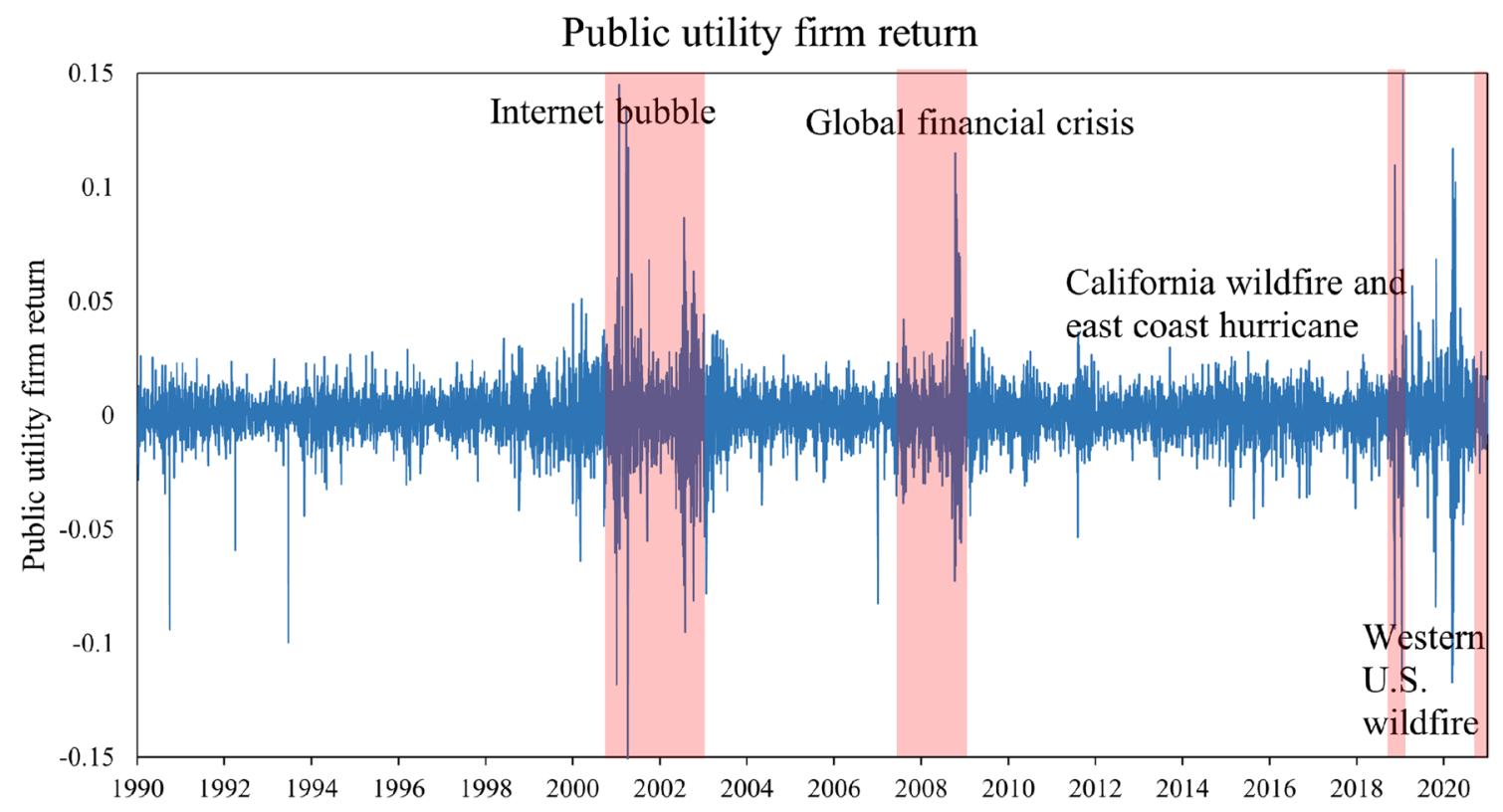

Fig. 8 Daily prices for the index of five major public utility companies from 1/2/1990 to 12/30/2020

hurricanes on the East coast of US in 2018 and more recent Western US wildfires in the summer of 2020.

3. Crude Oil Indicator

Crude oil is a global commodity that trades in markets around the world, both as spot oil and via derivatives contracts. Crude oil is the most important and commonly traded commodity in the world as it is the primary source of energy production. To construct the indicator for crude oil, we use the futures price of crude oil as an index since Central banks and the International Monetary Fund (IMF) mainly use oil futures contract prices as their gauge for the level of oil prices. Specifically, we use the daily price of CME Crude Oil Future as the indicator.

As demand for oil goes up, crude oil futures increase in price. The largest run-up of crude oil prices was right before the global financial crisis in 2008 followed by the largest decline in our time period (from $\$ 140$ per barrel to $\$ 40$ per barrel). In 2014-2015, the world experienced the oil glut where a serious surplus of crude oil resulted in the plunge of oil prices during this time period. Crude oil prices are also related to natural disasters and spiked during Hurricanes Katrina (2005), Rita (2005), and Florence (2018) (see Fig. 9).

4. Natural Gas Indicator

Natural Gas is a traded commodity with many industrial and commercial applications. In the United States, it is traded as a futures contract on the New York Mercantile Exchange. The price of natural gas is mainly driven by supply and demand fundamentals. It may also be linked to the price of crude oil and petroleum prod- ucts. To construct the indicator for natural gas, we use the Henry Hub Natural Gas Futures price as an index.

As demand for natural gas goes up, natural gas futures increase in price. The largest run-up of natural gas prices was right before the global financial crisis in 2008 followed by the largest decline in our time period. In addition to financial crises (Internet bubble of 2000 and global financial crisis of 2008), natural gas prices are impacted by natural disasters such as hurricanes Katrina (2005), Rita (2005), and Florence (2018) (see Fig. 9).

\section{Coal Indicator}

To construct the indicator for coal, we use the Thermal Coal Historical Spot Price as an index. Spot price is the price for a one-time open market transaction for immediate delivery purchased on the spot at current market rates. Coal prices have historically been lower and more stable than oil and gas prices.

Demand for coal has resulted in strong price movements in the commodity itself. Before the 2008 Global Financial Crisis, prices for coal experienced a major uptrend, going from $\$ 50$ per short ton in 2006 to almost $\$ 140$ per short ton in 2008. Coal prices are also impacted by natural disasters such as hurricanes Katrina (2005), Rita (2005), and Florence (2018) (see Fig. 9).

\section{Electricity Indicator}

Electricity is a commodity capable of being bought, sold, and traded. Electricity futures and other derivatives can help market participants manage, or hedge, price risks in a competitive electricity market. Futures contracts are legally binding that call for the future delivery of the commodity. To construct the indicator for electric- 

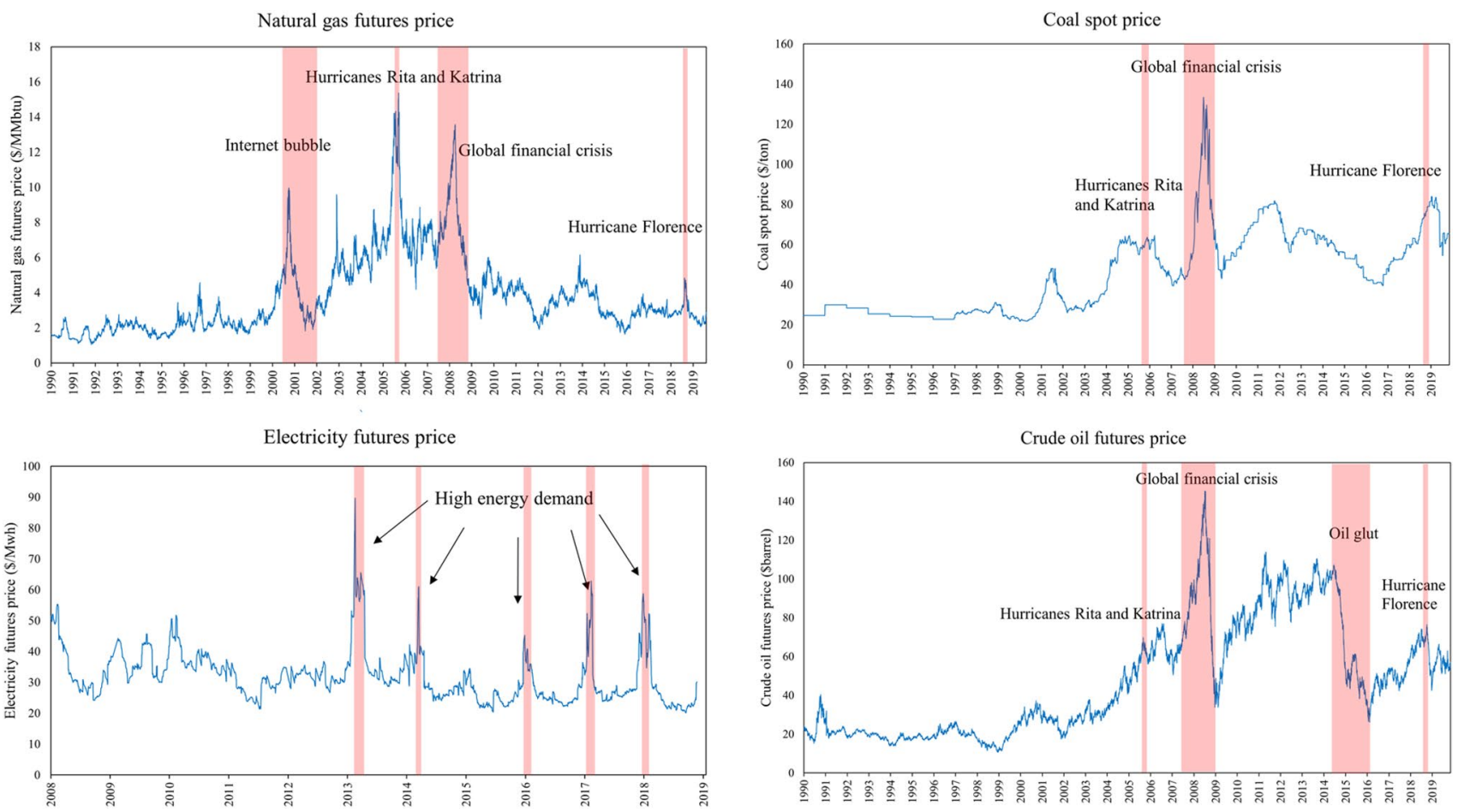

Fig. 9 Daily prices for natural gas, coal, crude oil, and electricity. Coal and crude oil data are available from 1/2/1990 to 11/5/2019. Natural gas futures are available from 4/30/1990 to $11 / 5 / 2019$ and electricity futures data is from 12/15/2008 to 11/5/2019

ity, we use the PJM Western Hub Real-Time Off-Peak Calendar-Month 5 MW Futures price as an index.

Electricity prices are a function of conditions of the economy, demand for electricity, and prices of electricity inputs such as natural gas, crude oil, and coal. During our sample period, we show that electricity prices spiked during the financial crisis (2008) and during high energy demand caused by cold weather in the beginning of 2013, 2014, 2016, 2017, and 2018 (see Fig. 9). 2014 and 2017 saw the spike in natural gas prices. 2013, 2014, and 2018 saw the spike in crude oil futures prices.

While electricity price is listed as a finance CRI, it also is an electric energy CRI. Not only do CRIs generate risks that can spill over into other domains but also many CRIs do not conveniently fit in siloed domains. Through this network analysis approach, the role of CRIs across multiple domains becomes increasingly apparent.

\subsection{Summary of CRIs}

In this section, we summarize top CRIs from each domain (climate, hydrology, agriculture, ecology, space weather, and finance) that relate to electric power grid. For each domain, we provide Jupyter Notebooks to illustrate and provide a foundation for further exploration of the domainspecific CRIs outlined in this manuscript (see Supplementary Information). These are useful tools to facilitate interaction between data scientists and domain scientists.

\begin{tabular}{|c|c|c|c|}
\hline Domain & CRI & $\begin{array}{l}\text { Affected } \\
\text { by grid }\end{array}$ & Affects grid \\
\hline Climate & $\begin{array}{l}\text { Anomalies (rainfall, } \\
\text { temperature) }\end{array}$ & No & Yes \\
\hline Climate & $\begin{array}{l}\text { Standard Precipitation } \\
\text { Index (SPI) }\end{array}$ & No & Yes \\
\hline Climate & $\begin{array}{l}\text { Anomalies of number of } \\
\text { days a criteria is met } \\
\left.\text { (e.g., }>1 \mathrm{~mm} ; \leq 0^{\circ} \mathrm{C}\right)\end{array}$ & No & Yes \\
\hline Hydrology & Streamflow & Yes & Yes \\
\hline Hydrology & Drought indices & No & Yes \\
\hline Hydrology & Groundwater levels & Yes & Yes \\
\hline Agriculture & Irrigation demand & No & Yes \\
\hline Agriculture & Crop biomass production & Yes & Yes \\
\hline Agriculture & Vegetation Index (EVI) & Yes & Yes \\
\hline Ecology & $\begin{array}{l}\text { Population abundance } \\
\text { (Living Planet Index) }\end{array}$ & Yes & Yes \\
\hline Ecology & $\begin{array}{l}\text { Bird abundance (USGS } \\
\text { Breeding Bird Survey) }\end{array}$ & Yes & Yes \\
\hline Ecology & $\begin{array}{l}\text { Biodiversity (Shannon } \\
\text { and Simpson indices) }\end{array}$ & Yes & Yes \\
\hline Space Weather & Kp Index & No & Yes \\
\hline
\end{tabular}




\begin{tabular}{|c|c|c|c|}
\hline Domain & CRI & $\begin{array}{l}\text { Affected } \\
\text { by grid }\end{array}$ & Affects grid \\
\hline Space Weather & $\begin{array}{l}\text { Global SuperMAG indi- } \\
\text { ces (SMR and SME) }\end{array}$ & No & Yes \\
\hline Space Weather & $\begin{array}{l}\text { Regional SuperMAG } \\
\text { indices (SMR and } \\
\text { SME) }\end{array}$ & No & Yes \\
\hline Space Weather & $\begin{array}{l}\text { Power Grid Geomagneti- } \\
\text { cally Induced Currents } \\
\text { (GICs) }\end{array}$ & No & Yes \\
\hline Finance & $\begin{array}{l}\text { Volatility Indicator } \\
\text { (VIX) }\end{array}$ & Yes & Yes \\
\hline Finance & Public Utility Indicator & Yes & Yes \\
\hline Finance & Crude Oil Indicator & Yes & Yes \\
\hline Finance & Natural Gas Indicator & Yes & Yes \\
\hline Finance & Coal Indicator & Yes & Yes \\
\hline Finance & Electricity Indicator & Yes & Yes \\
\hline
\end{tabular}

\section{Electric energy}

Realization of risk in the power grid The negative outcome associated with risk in the electrical grid is a power supply interruption. The risk could originate wholly from within the electric energy domain or as a result of spillovers from other domains (as discussed in Sect. 2). A power supply interruption can be defined as the total loss of electric power on one or more normally energized conductors to one or more customers connected to the distribution portion of the system (Subcommittee 2012). This does not include any of the power quality issues such as sags, swells, impulses, or harmonics (Subcommittee 2012). In contrast, an outage is the loss of ability of a component to deliver power, which may or may not result in an interruption (Subcommittee 2012). The severity of power supply interruptions also depends on the domain where the risk is emanating from, for example, risks from the space weather domain as a result of magnetic storms tend to result in major electric grid disturbance while risks emanating from ecology — as a result of interference by animals, e.g., squirrels and birds, are comparatively less severe.

Existing Electric Energy CRIs CRIs in the electric energy domain relate to either the potential for or severity of a power supply interruption. Examples of existing electric energy CRIs include the following:

1. System Average Interruption Duration Index (SAIDI) One of the most widely used metric for quantifying disturbances on the power grid is the SAIDI. According to the IEEE Guide for Electric Power Distribution Reliability Indices (Subcommittee 2012), this metric is used to quantify the amount of time, on average, custom- ers' electricity is disrupted for longer than five minutes. SAIDI is defined as follows:

SAIDI $=\frac{\sum r_{i} N_{i}}{N}$

2. System Average Interruption Frequency Index (SAIFI) SAIFI on the other hand indicates how often the average customer experiences a sustained interruption over a predefined period of time. it is defined as follows:

$\mathrm{SAIFI}=\frac{\sum N_{i}}{N}$

where $r_{i}$ is the duration of each interruption $i, N_{i}$ is the amount of customers affected, and $N$ is the total number of customers being serviced (Subcommittee 2012).

3. Reserve Margin Reserve margin is an energy system metric used to quantify the adequacy of generation resources to satisfy demand (NERC 2013). As opposed to aforementioned CRIs, the reserve margin can indicate a potential to result in a power supply interruption. It measures (as shown in Eq. (4)) the percentage of available generation that exceeds the peak demand where "available generation" is the maximum supply available.

$R M=\frac{G_{a v}-D}{D}$

where $R M$ is the reserve margin, $G_{a v}$ is the available generation capacity, and $D$ is the peak demand.

The System Average Interruption Duration Index (SAIDI) and the System Average Interruption Frequency Index (SAIFI) are examples of indices that relate to a failure of the power system since they can only be calculated after a failure has occurred. Both SAIDI and SAIFI are very useful for measuring the resulting risk outcome on the electrical grid and they can be very useful in developing strategies for improving grid reliability.

Reserve margin serves various purposes depending on the context within which it is used. In the US Electricity sector, planning reserve margin, PRM, is used to quantify the capacity build-out required to meet an adequacy threshold. North American Electric Reliability Corporation (NERC) uses it to evaluate resource planning decisions uniquely for each region in the US. In the absence of regional targets, NERC assigns a 15\% reserve margin for thermal systems and 10\% for hydrosystems (NERC 2020). An issue with the reserve margin is that the metric does not quantify the specific impact of each generator in meeting demand. The definition and evaluation of the reserve margin is changing to adapt to the transformation of the electrical grid by accounting for penetration of more variable resources, such as wind and solar. It can, therefore, be modified to account for resource availability and forced outage rates. The reserve margin can also 

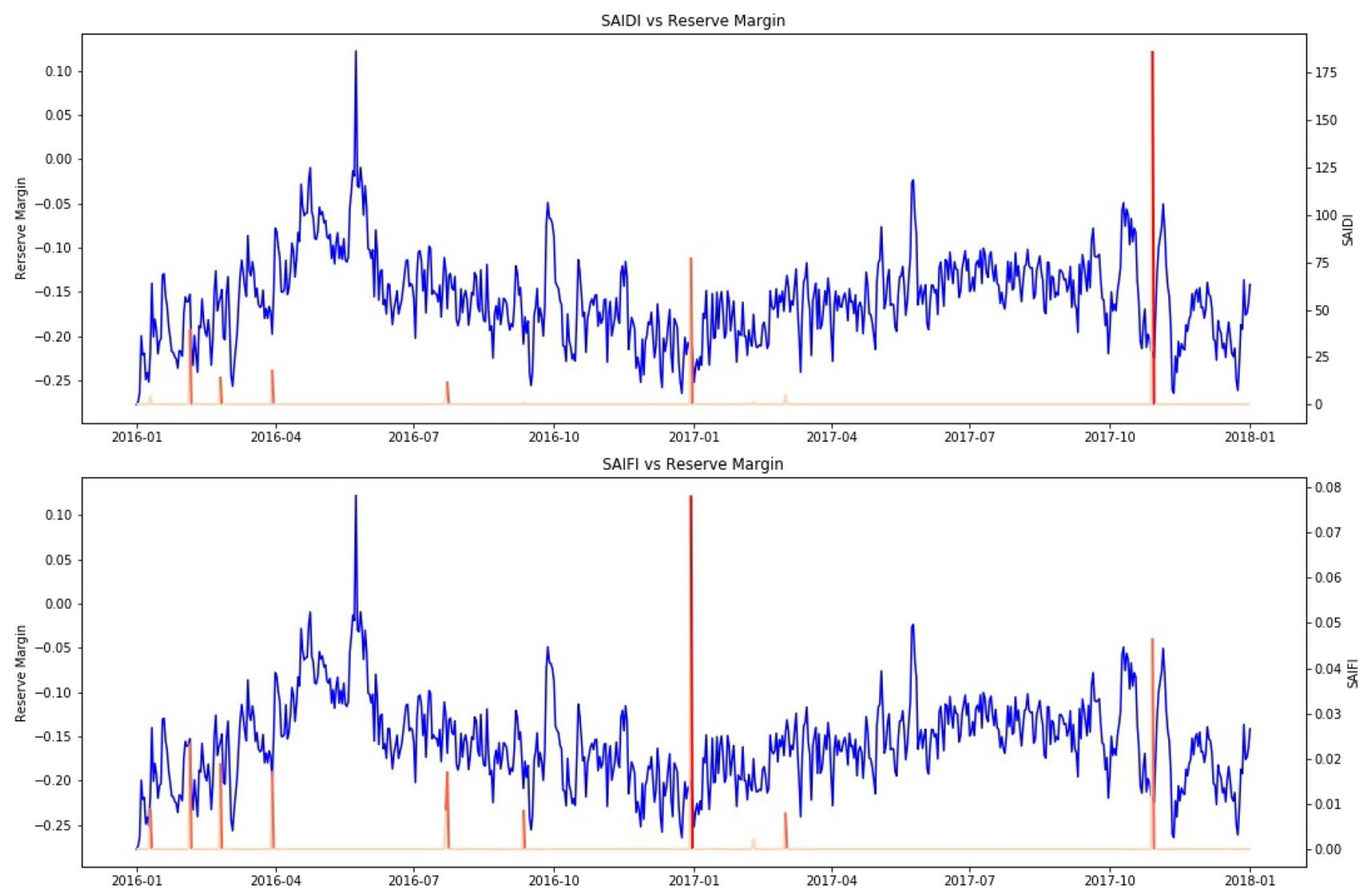

Fig. 10 Electric Energy CRIs for ISO New England between 2016 and 2018. The variables shown are SAIDI and the reserve margin (top panel); SAIFI and the reserve margin (bottom panel). The red lines indicate the severity of the power supply interruption (SAIDI or

point to supply security, especially in cases where generation imports are necessary to satisfy peak demand.

Figure 10 shows the plot of SAIDI and SAIFI against the reserve margin. ${ }^{6}$ Negative values of the reserve margin indicate that external generation is needed to satisfy demand. A decrease in reserve margin is observed around January, 2017 and this coincides with a spike in SAIFI and SAIDI.

SAIDI, SAIFI, and Reserve Margin are provided as illustrative examples of electric energy CRIs. Please note that numerous other risk and reliability indices exist, such as the expected energy not supplied (EENS) and its associated costs, i.e., customer interruption costs.

Available data sets for calculating existing Electric Energy CRIs Reliability data consisting of SAIDI and SAIFI are reported annually (available from 2013 to 2018) by the US Energy Information Administration (US Energy Information Administration 2019). However, outage data reported in the

\footnotetext{
${ }^{6}$ Here, the reserve margin has been calculated using the actual generation and demand (so the generation does not necessarily represent the maximum available capacity).
}

SAIFI). The blue curves indicate the reserve margin based on historical data of generation and demand for each day within the time period (Commonwealth of Massachusetts 2020)

OE-417 Electric Disturbance report (for major outages available 2000 till present) (Office of Cybersecurity Energy Security \& Emergency Response 2020) and those collected at the state/utility level (an example is the Massachusetts Outage Data (Commonwealth of Massachusetts 2020) usually provide higher spatial and temporal resolution for these indices.

\section{Systemic Risk Indicators (SRI)}

This survey shows that the electrical grid and its resilience are not defined and operated in a closed system. Critical risk indicators in the electric energy domain are directly impacted by other domains such as climate, ecology, hydrology, agriculture, space weather, and finance. We identified CRIs in each of the domains that are directly related to electrical grid vulnerability. Although an existing CRI in one domain may be important for modeling risk to the power grid, individual CRIs may only be important during specified scenarios or time frames (e.g., space weather CRIs may only exhibit strong signals during solar storms). 
Moreover, in addition to considering bilateral relationships with each human-natural domain and the electric energy domain, it is important to look at systemic interconnections between CRIs among domains. We borrow the concept of systemic risk and systemic risk measures from finance literature. In finance, systemic risk measures the risk of financial system instability, which is caused or exacerbated by idiosyncratic events or catastrophic conditions in financial intermediaries (Billio et al. 2012). It is the risk that the collapse of one financial institution could cause other connected financial institutions to fail and harm the real economy as a whole. In our setting, systemic risk measures will capture the health of the interconnected human-natural system and the interdependencies between CRIs in each of the domain; we refer to the trans-domain systemic risk measures as Systemic Risk Indicators (SRIs). Below we provide narrative for additional human-natural domain connections and develop a framework for assessing systemic risk and building systemic risk measures for human-natural domains.

\subsection{Additional examples of domain interconnections}

Climate risk indicators directly relate with other domains such as ecology, hydrology, and agriculture. Excess temperatures above a certain threshold are known to favor the growth of certain crops. Rainfall is important to farmers, especially those who practice rain-fed agriculture, and so monthly anomalies of rainfall are a relevant CRI for agriculture. Monthly (or seasonal) aggregation of rainfall may, however, not be the best CRI for rain-fed agriculture as the sequence of the rainfall events during the month (season) matter as much as, if not more than, the total rainfall in that period. With the same amount of rain during the crop growing season, outcomes to the crop health may be drastically different if the rainfall is evenly spread in different days, rather than if it rains in one or two extreme events. Therefore, the number of wet days (days above a certain precipitation threshold, e.g., $1 \mathrm{~mm}$ ) may be a better CRI to agricultural yields.

Much of the same reasoning can be applied to ecology, as the activity and developmental rates of wildlife and their habitats vary according to daily and seasonal weather (temperature, precipitation, and wind speeds; Doostan and Chowdhury 2019) or accumulated heat (growing degree days; Murray 2020). Therefore, weather data can account for biases in species abundance data due to variation in detection probability. Threshold-based analyses may be good indicators for identifying key increases or reductions of species abundance that result in changes to biodiversity that can be accompanied with high-risk outcomes in other domains. Broader scale spatial and temporal climate anomalies may be more applicable to measures of biodiversity change. Regional changes in climate can change habitat suitability. This can lead to some species declining in abundance and others increasing depending on their adaptability to the changes in climate. Overall, this causes changes in species compositions and shifts in species distributions (Diamond 2018).

Additionally, hydrologic risk can spill over to other domains such as aquatic ecosystem health (Falke et al. 2011). The drought-induced soil moisture deficit affects vegetation productivity and crop yield. Irrigation demand under droughts is generally met with groundwater pumping, which requires electricity (Scott 2013). As indicated in the Hydrology section, the CRI is "drought," a longerterm building up process that starts with sustained deficit in rainfall (meteorological drought) that may turn into agricultural drought, hydrological drought, and below-average hydropower production. Climate CRIs relevant to hydrology are indicators such as the Standardized Precipitation Index (SPI) that indicates the build-up of rainfall deficit (or excess) for the past 3 to 24 months. While climate inputs are the driving forces, the hydrologic system strongly modulates the input signal. The variable that is more directly related to stakeholders, such as reservoir operators, and civil infrastructure is streamflow. From the perspective of monitoring and forecasting future risks, monthly outlook of streamflow distributions can be a valuable CRI.

Despite their positive impacts on agricultural productivity, electrification can also generate negative spillovers. The availability of electricity is often accompanied by environmental costs, for example, groundwater overexploitation (Badiani-Magnusson and Jessoe 2018). Policies that are related to electricity price (e.g., subsidy) are therefore particularly important, for example, in India, where groundwater irrigates $70 \%$ of irrigated agricultural land (Badiani-Magnusson and Jessoe 2018). The process of electricity generation (e.g., burning coal, oil or natural gas, hydropower) is also not without economic, social, and environmental impacts. For example, hydropower operation is determined by scheduling that typically includes several river basins (Gonzalez et al. 2020). The scheduling alters water levels and downstream water flow patterns (Castelletti et al. 2008), affecting habitats of different flora and fauna. Although part of the electricity generated by hydropower is also used for irrigation pumping machines, there may exist a competition of water use between power generation with irrigation itself (e.g., when streamflow is limited; Gonzalez et al. 2020).

Electric energy domain can also affect agriculture through at least two different mechanisms. First, the US electric power sector was responsible for roughly $30 \%$ of total US energy-related $\mathrm{CO}_{2}$ emissions (US Energy Information Administration 2021). These emissions may create negative feedback to agricultural production due to its effect 
Electric Energy CRI2

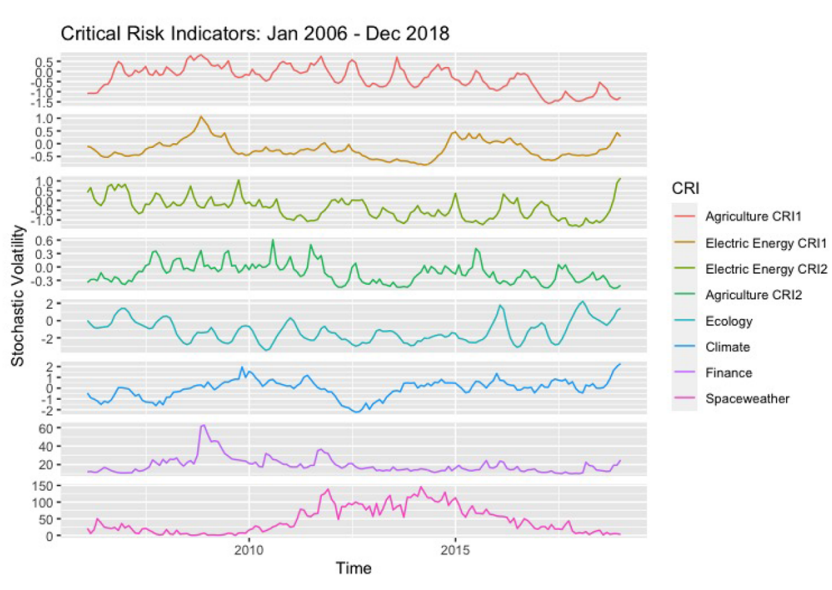

(a) Domain CRIs Monthly Time Series, Jan 2006 to Dec 2018.

Fig. 11 Initial SRI analysis results

on climate while offering $\mathrm{CO}_{2}$ fertilizer effects. Second, if power supply interruption occurs, the industrial sector (including agriculture) may experience significant reduction in productivity as its outage-per-customer cost (USD 3253 per one-hour outage) is significantly higher than commercial (USD 886) and residential sectors (USD 2.7; based on currency value in 2002; LaCommare and Eto 2004).

In summary, there are many explicit interconnections among human-natural domains that have been studied. Each domain has a unique risk profile and specific CRIs. We next move to developing a framework for connecting these domains and assessing resulting systemic risk.

\subsection{Systemic risk indicators for human-natural domain interconnections}

We broadly define trans-domain or holistic systemic risk as any set of circumstances that threatens the stability of our society and natural world; in our case, systemic risk concerns the overall stability and reliability of our power grid system at large. Systemic risk arises endogenously from a nexus of interconnected processes or systems. It is a function of the connections between the fundamental structure of these diverse components, and thus causality and dynamics play a central role. We propose using a dynamic model of CRIs from many domains (Fig. 11a), in order to (1) define a trans-domain risk nexus represented as a network or graph, and (2) construct SRIs as functions of connectivity from that network.
As a starting point, we introduce the vector autoregression (VAR) model for dynamically modeling CRIs. It remains as the standard-bearer for macroeconomic forecasting (Sims 1980) and is widely applied in numerous fields, including climatology, neuroscience, and signal processing. Suppose we have computed a historical sequence of $i=1, \ldots, d$ distinct CRIs, within and across several domains, and that they are aligned with common time index $t=1, \ldots, n$. For now, also suppose the CRIs are approximately stationary over this time period and meancentered. Let $\mathbf{y}_{t}$ denote the $d$ dimensional vectorization of these CRIs at time $t$, such that the $i$ th component of $\mathbf{y}_{t}$ corresponds to $\mathrm{CRI}_{i}(t)$. In a VAR model, the series $\mathbf{y}_{t}$ is modeled as a function of its own past value $\mathbf{y}_{t-1}$, which may be standardized for better parameter estimation. More precisely,

$\mathbf{y}_{t}=\Phi \mathbf{y}_{t-1}+\mathbf{a}_{t}$

where $\Phi$ is the $d \times d$ autoregressive parameter matrix, $\mathbf{a}_{t}$ denotes a $d$ dimensional mean-zero white noise (serially uncorrelated) vector time series with $d \times d$ nonsingular (contemporaneous) covariance matrix $\Sigma_{a}$. This VAR model also allows easy extensions for incorporating additional lagged values (e.g., $\mathbf{y}_{t-2}$, etc.), straightforward forecasting at multiple horizons including forecast intervals, simple forecast updating, and (impulse) response function analysis (Tsay 2013). Further extensions are possible to account for non-stationarity and multi-level spatial-temporal resolution. To account for potential false discoveries across 
a large collection of CRIs, we can utilize any number of multiple testing methods (Benjamini and Hochberg 1995) that control for False Discovery Rate (FDR). Based on our estimated parameters, we can construct a network of intertemporal dependencies (Granger causality) based on significance thresholds and utilize the network summary statistics, such as connectivity, as a SRI. This graph can either be unweighted where an edge between two nodes indicates existence of a significant inter-temporal dependency, or can be weighted by the magnitude of the dependency. In finance, for example, Granger causality provides measurements of directional connection between financial institutions over two consecutive time periods. Using Granger-causality network, Billio et al. (2012) found that during the global financial crisis of 2007-2009, returns of banks and insurers seem to have more significant impact on the returns of hedge funds and broker/dealers than vice versa.

After proper estimation of inter-temporal relationships (e.g., Granger causality), we propose the following network-based SRIs based on Granger-causality network of interconnected CRIs: eigenvector centrality and degrees of Granger causality. The eigenvector centrality measures the importance of a CRI in a network by assigning relative scores to CRIs based on how connected they are to the rest of the network. First, define the adjacency matrix $A$ as the matrix with elements: $[A]_{j i}=(j \rightarrow i)$, where an edge is determined by if a statistically significant Granger-causal relationship exists between two nodes. This edge can either be weighted or unweighted. The eigenvector centrality measure is the eigenvector $v$ of the adjacency matrix associated with eigenvalue 1, i.e., in matrix form: $A v=v$. Degree of Granger causality (DGC) is the fraction of statistically significant Granger-causality relationships among all $N(N-1)$ pairs of $N$ CRIs, and is one way to summarize connectivity over the entire graph. If the adjacency matrix has non-negative entries, a unique solution is guaranteed to exist by the Perron-Frobenius theorem.

As an illustrative example, consider the set of $d=8$ CRIs across six human-natural domains measured monthly from January 2006 to December 2018. The domains (agriculture, electric energy, ecology, climate, finance, and space weather) and weekly time series of individual CRIs are shown in (Fig. 11a). Note that some domains can have more than one CRI. In this case, we use two CRI measures each for agriculture and electric energy domains. From the estimate of $\Phi$, the inter-connectivity can be determined by statistically significant off-diagonal coefficients, which produce a model-estimated trans-domain nexus (Fig. 11b). Specifically, we construct a Granger-causality network from VAR(1) model, where directed arrows indicate temporal dependence, arrow width indicates magnitude of the relationship, and color (blue vs. red) indicates positive vs. negative relationships. We observe that space weather is an exogenous CRI that affects all domains but is not impacted by any other domain. In comparison, the finance domain is strongly affected by other domains but bears no impact on others (no out-going arrows). Some domains, such as electric energy, agriculture, ecology, and climate are more interdependent, and a shock to one CRI can easily propagate to others. The total number of significant Granger-causal relationships is 15 , giving a DGC of $26.8 \%$ which indicates moderate connectivity. While Fig. 1 shows a general schematic and nexus of interconnections, Fig. $11 \mathrm{~b}$ provides a specific example of how a Granger-causality network for SRIs can be constructed and interpreted.

An alternative measure to consider is cosine similarity (Girardi et al. 2021) between CRIs. As an example from financial institutions, Girardi et al. (2021) found that similar institutions' asset holdings (those with high cosine similarity) lead to massive joint sales that leads to subsequent drop in asset prices, during and after large disasters such as Hurricanes Harvey and Rita. Other systemic risk measures that focus on probabilities of loss and network methods have been introduced in the finance and economics literature. Bisias et al. (2012) provides a survey of the following systemic risk measures: marginal expected shortfall (MES), SRISK, turbulence measure, network connectedness method (PCA, and Granger Causality), and volatility measure. It is important to emphasize that no one measure will be best for capturing systemic risk in human-natural systems, as the performance of individual metrics can vary at different spatial and temporal scales and depending on the specific components measured (Bakkensen et al. 2017). Frameworks for combining multiple metrics have been proposed to comprehensively assess the resilience of energy systems (e.g., Roege et al. 2014; Gatto and Drago 2020). Similarly, a dashboard of different systemic risk measures can provide a more holistic understanding of trans-domain interactions.

\section{Supplementary information}

Jupyter Notebooks that illustrate the domain-specific CRIs outlined in our manuscript, including sample data and exploratorycode, can be found at https://github.com/ rmcgranaghan/Critical-Risk-Indicators-CRIs-for-the-elect ric-power-grid/.

Acknowledgements Funding was provided by the NSF Harnessing the Data Revolution (HDR) program, "Collaborative Research: Predictive Risk Investigation SysteM (PRISM) for Multi-layer Dynamic Interconnection Analysis" (Awards \#1940160, 2023755, 1940176, 1940190, 1940208, 1940223, 1940276, 1940291, and 1940696). R. McGranaghan was partially supported under the NSF Convergence Accelerator Award to the Convergence Hub for the Exploration of Space Science 
(CHESS) team (NSF Award Number: 1937152). We would like to thank Suoan Gao (UMASS Amherst) for research assistance.

\section{Declarations}

Conflict of interest The authors declare that they have no conflicts of interest.

\section{References}

Abatzoglou JT (2013) Development of gridded surface meteorological data for ecological applications and modelling. Int J Climatol 33(1):121-131. https://doi.org/10.1002/joc.3413

Abedi A, Romerio F, Gaudard L (2018) Review of major approaches to analyze vulnerability in power system. Reliab Eng Syst Saf. https://doi.org/10.1016/j.ress.2018.11.019

Adler RF, Sapiano MRP, Huffman GJ, Wang JJ, Gu G, Bolvin D, Chiu L, Schneider U, Becker A, Nelkin E, Xie P, Ferraro R, Shin DB (2018) The Global Precipitation Climatology Project (GPCP) monthly analysis (new version 2.3) and a review of global precipitation. Atmosphere 9(4):138

Akhgarzarandy F, Wang H, Farzinfar M (2021) Optimal resiliencyoriented charging station allocation for electric vehicles considering uncertainties. Int Trans Electr Energy Syst 31(4):e12799. https://doi.org/10.1002/2050-7038.12799

Allen-Dumas MR, Binita KC, Colin I Cunliff (2019) Extreme weather and climate vulnerabilities of the electric grid: a summary of environmental sensitivity quantification methods. Tech. rep., http://www.osti.gov/scitech/

Arianos S, Bompard E, Carbone A, Xue F (2009) Power grid vulnerability: a complex network approach. Chaos 19(1):013119

Aven T, Ben-Haim Y, Boje Andersen H, Cox T, Droguett EL, Greenberg M, Guikema S, Kröger W, Renn O, Thompson KM, et al. (2018) Society for risk analysis glossary. Soc Risk Anal

Badiani-Magnusson R, Jessoe K (2018) Electricity prices, groundwater, and agriculture: the environmental and agricultural impacts of electricity subsidies in India. In: Agricultural Productivity and Producer Behavior. University of Chicago Press, pp 157-183

Bakkensen L, Fox-Lent C, Read L, Linkov I (2017) Validating resilience and vulnerability indices in the context of natural disasters. Risk Anal 37(5):982-1004. https://doi.org/10.1111/risa.12677

Balducci PJ, Roop JM, Schienbein LA, DeSteese JG, Weimar MR (2002) Electric power interruption cost estimates for individual industries, sectors, and US economy. Tech. rep., Pacific Northwest National Lab. (PNNL), Richland

Bartels J, Heck NH, Johnston HF (1939) The three-hour-range index measuring geomagnetic activity. Terr Magn Atmos Electr 44(4):411-454. https://doi.org/10.1029/TE044i004p00411

Benjamini Y, Hochberg Y (1995) Controlling the false discovery rate: a practical and powerful approach to multiple testing. J R Stat Soc Ser B 57(1):289-300

Billio M, Getmansky Sherman M, Lo AW, Pelizzon L (2012) Econometric measures of connectedness and systemic risk in the finance and insurance sectors. J Financ Econ 104(3):535-559

Bisias D, Flood M, Lo AW, Valavanis S (2012) A survey of systemic risk analytics. Annu Rev Financ Econ 4(1):255-296

Borovsky JE (2013) Physics-based solar wind driver functions for the magnetosphere: combining the reconnection-coupled MHD generator with the viscous interaction. J Geophys Res 118(11):7119-7150. https://doi.org/10.1002/jgra.50557

Boteler DH (2013) Space weather effects on power systems. Am Geophys Union 125:347-352. https://doi.org/10.1029/GM125 p0347
Brand F, Jax K (2007) Focusing the meaning(s) of resilience: resilience as a descriptive concept and a boundary object. Ecol Soc 12(1):120123. https://doi.org/10.5751/ES-02029-120123

Brondizio ES, Settele J, Díaz S, Ngo HT et al (2019) Global assessment report on biodiversity and ecosystem services of the intergovernmental science-policy platform on biodiversity and ecosystem services. IPBES secretariat, Bonn

Brown MT, Harnish M (2014) Many industrial electricity customers are farmers. Tech. rep, US Energy Information Administration

Buckland S, Magurran A, Green R, Fewster R (2005) Monitoring change in biodiversity through composite indices. Philos Trans R Soc B 360(1454):243-254. https://doi.org/10.1098/rstb.2004. 1589

Buldyrev S, Parshani R, Paul G, Stanley H, Havlin S (2010) Catastrophic cascade of failures in interdependent networks. Nature 464:1025-8. https://doi.org/10.1038/nature08932

California ISO (2021) Root cause analysis: Mid-August 2020 extreme heat wave. Tech. rep., http://www.caiso.com/Documents/FinalRoot-Cause-Analysis-Mid-August-2020-Extreme-Heat-Wave.pdf

CARB (2015) Greenhouse gas inventory data-2000 to 2012. Tech. rep., California Air Resources Board. http://www.arb.ca.gov/cc/ inventory/data/data.htm

Castelletti A, Pianosi F, Soncini-Sessa R (2008) Water reservoir control under economic, social and environmental constraints. Automatica 44(6):1595-1607

Chen M, Xie P (2008) CPC unified gauge-based analysis of global daily precipitation. Western Pacific Geophysics Meeting, Cairns

Chen M, Shi W, Xie P, Silva VBS, Kousky VE, Wayne Higgins R, Janowiak JE (2008) Assessing objective techniques for gaugebased analyses of global daily precipitation. J Geophys Res. https://doi.org/10.1029/2007JD009132

Chen X, Thorp KR, Ouyang Z, Hou Y, Zhou B, Li Y (2019) Energy consumption due to groundwater pumping for irrigation in the North China Plain. Sci The Total Environ 669:1033-1042

Chow M, Taylor L (1995) Analysis and prevention of animal-caused faults in power distribution systems. IEEE Trans Power Deliv 10(2):995-1001

Ciapessoni E, Cirio D, Pitto A, Panteli M, Van Harte M, Mak C (2019) Defining power system resilience. CIGRE WG C447

Collen B, Loh J, Whitmee S, McRAE L, Amin R, Baillie JEM (2009) Monitoring change in vertebrate abundance: the Living Planet Index. Conserv Biol 23(2):317-327. https://doi.org/10.1111/j. 1523-1739.2008.01117.x

Commonwealth of Massachusetts (2020) Historic power outages. https://www.mass.gov/info-details/power-outages\#historicpower-outages-

Davis TN, Sugiura M (1966) Auroral electrojet activity index AE and its universal time variations. J Geophys Res 71(3):785-801. https://doi.org/10.1029/JZ071i003p00785

Diamond SE (2018) Contemporary climate-driven range shifts: putting evolution back on the table. Funct Ecol 32(7):1652-1665. https:// doi.org/10.1111/1365-2435.13095

Dian S, Cheng P, Ye Q, Wu J, Luo R, Wang C, Hui D, Zhou N, Zou D, Yu Q, Gong X (2019) Integrating wildfires propagation prediction into early warning of electrical transmission line outages. IEEE Access 7:27586-27603

Doorman G, Uhlen K, Kjolle G, Huse E (2006) Vulnerability analysis of the nordic power system. IEEE Trans Power Syst 21(1):402410. https://doi.org/10.1109/TPWRS.2005.857849

Doostan M, Chowdhury B (2019) Statistical analysis of animal-related outages in power distribution systems-a case study. In: 2019 IEEE Power Energy Society General Meeting (PESGM), pp 1-5. https://doi.org/10.1109/PESGM40551.2019.8973448

Falke JA, Fausch KD, Magelky R, Aldred A, Durnford DS, Riley LK, Oad R (2011) The role of groundwater pumping and drought in shaping ecological futures for stream fishes in a dryland river 
basin of the western great plains, USA. Ecohydrology 4(5):682697. https://doi.org/10.1002/eco.158

Feng D, Fang K, Shen C (2020) Enhancing streamflow forecast and extracting insights using long-short term memory networks with data integration at continental scales. Water Resour Res 56(9):e2019WR026793. https://doi.org/10.1029/2019WR026793

Feron S, Cordero RR, Damiani A, Jackson RB (2021) Climate change extremes and photovoltaic power output. Nat Sustain 4(3):270-276

Galaitsi SE, Keisler JM, Trump BD, Linkov I (2020) The need to reconcile concepts that characterize systems facing threats. Risk Anal 41(1):3-15

Gatto A, Drago C (2020) Measuring and modeling energy resilience. Ecol Econ 172:106527

Gaudard L, Romerio F (2014) The future of hydropower in Europe: interconnecting climate, markets and policies. Environ Sci Policy 37:172-181

Gelaro R, McCarty W, Suárez MJ, Todling R, Molod A, Takacs L, Randles CA, Darmenov A, Bosilovich MG, Reichle R, Wargan K, Coy L, Cullather R, Draper C, Akella S, Buchard V, Conaty A, da Silva AM, Gu W, Kim GK, Koster R, Lucchesi R, Merkova D, Nielsen JE, Partyka G, Pawson S, Putman W, Rienecker M, Schubert SD, Sienkiewicz M, Zhao B (2017) The modern-era retrospective analysis for research and applications, version 2 (merra-2). J Clim 30(14):5419-5454

Girardi G, Hanley KW, Nikolova S, Pelizzon L, Sherman MG (2021) Portfolio similarity and asset liquidation in the insurance industry. J Financ Econ

Gjerloev JW (2009) A global ground-based magnetometer initiative. Eos, Trans Am Geophys Union 90(27):230-231. https://doi.org/ 10.1029/2009EO270002

Gleick P (2015) Impacts of California's ongoing drought: hydroelectricity generation. Tech. rep., Pacific Institute, Oakland, California, https://pacinst.org/publication/impacts-of-californias-ongoi ng-drought-hydroelectricity-generation/

Golan MS, Jernegan LH, Linkov I (2020) Trends and applications of resilience analytics in supply chain modeling: systematic literature review in the context of the COVID-19 pandemic. Environ Syst Decis 40(2):222-243. https://doi.org/10.1007/ s10669-020-09777-w

Gonzalez JM, Olivares MA, Medellín-Azuara J, Moreno R (2020) Multipurpose reservoir operation: a multi-scale tradeoff analysis between hydropower generation and irrigated agriculture. Water Resour Manag 34:2837-2849

Guenang GM, Kamga FM (2014) Computation of the Standardized Precipitation Index (SPI) and its use to assess drought occurrences in Cameroon over recent decades. J Appl Meteorol Climatol 53(10):2310-2324

Hicks S (2014) Energy for growing and harvesting crops is a large component for farm operating costs. US Energy Information Administration, Washington

Hynes W, Trump B, Love P, Linkov I (2020) Bouncing forward: a resilience approach to dealing with COVID-19 and future systemic shocks. Environ Syst Decis 40(2):174-184

Izadi M, Hosseinian SH, Dehghan S, Fakharian A, Amjady N (2021) A critical review on definitions, indices, and uncertainty characterization in resiliency-oriented operation of power systems. Int Trans Electr Energy Syst 31(1):e12680. https://doi.org/10.1002/ 2050-7038.12680

Jufri FH, Widiputra V, Jung J (2019) State-of-the-art review on power grid resilience to extreme weather events: definitions, frameworks, quantitative assessment methodologies, and enhancement strategies. Appl Energy 239:1049-1065. https:// doi.org/10.1016/j.apenergy.2019.02.017

Kanamura T, Õhashi K (2007) A structural model for electricity prices with spikes: measurement of spike risk and optimal policies for hydropower plant operation. Energy Econ 29(5):1010-1032

Kurth M, Kozlowski W, Ganin A, Mersky A, Leung B, Dykes J, Kitsak M, Linkov I (2020) Lack of resilience in transportation networks: economic implications. Transp Res Part D 86:102419

LaCommare KH, Eto JH (2004) Understanding the cost of power interruptions to US electricity consumers. Tech. rep., Lawrence Berkeley National Lab.(LBNL), Berkeley, CA

LaCommare KH, Eto Joseph H, Dunn Laurel N, Sohn Michael D (2018) Improving the estimated cost of sustained power interruptions to electricity customers. Electricity Markets \& Policy, Berkeley Lab

Lewis J, Severnini E (2014) The value of rural electricity: evidence from the rollout of the us power grid. Tech. rep

Lewis J, Severnini E (2020) Short-and long-run impacts of rural electrification: evidence from the historical rollout of the us power grid. J Dev Econ 143:102412

Li B, Rodell M, Zaitchik BF, Reichle RH, Koster RD, van Dam TM (2012) Assimilation of GRACE terrestrial water storage into a land surface model: evaluation and potential value for drought monitoring in western and central Europe. J Hydrol 446:103-115

Lin J, Yz Sun, Cheng L, Wz Gao (2012) Assessment of the power reduction of wind farms under extreme wind condition by a high resolution simulation model. Appl Energy 96:21-32

Maliszewski PJ, Larson EK, Perrings C (2012) Environmental determinants of unscheduled residential outages in the electrical power distribution of Phoenix, Arizona. Reliab Eng Syst Saf 99:161171. https://doi.org/10.1016/j.ress.2011.10.011

Marques AT, Santos CD, Hanssen F, Muñoz AR, Onrubia A, Wikelski M, Moreira F, Palmeirim JM, Silva JP (2019) Wind turbines cause functional habitat loss for migratory soaring birds. J Anim Ecol 89(1):93-103. https://doi.org/10.1111/1365-2656.12961

Mayes F (2017) Biomass and waste fuels made up 2\% of total U.S. electricity generation in (2016) Today in Energy. Tech. rep, US Energy Information Administration

Mccarthy MA, Moore AL, Krauss J, Morgan JW, Clements CF (2014) Linking indices for biodiversity monitoring to extinction risk theory. Conserv Biol 28(6):1575-1583. https://doi.org/10.1111/ cobi. 12308

Morris EK, Caruso T, Buscot F, Fischer M, Hancock C, Maier TS, Meiners T, Müller C, Obermaier E, Prati D, Socher SA, Sonnemann I, Wäschke N, Wubet T, Wurst S, Rillig MC (2014) Choosing and using diversity indices: insights for ecological applications from the German Biodiversity Exploratories. Ecol Evol 4(18):3514-3524

Murray M (2020) Using degree days to time treatments for insect pests. Utah State University Extension 2020 All Current Publications(978)

NERC (2013) Reliability metrics specifications sheet ALR 1-3 reserve margin. https://www.nerc.com/comm/PC/Performance Analysis Subcommittee PAS 2013/1-3 July 9.pdf

NERC (2020) M-1 Planning Reserve Margin. https://www.nerc.com/ $\mathrm{pa} / \mathrm{RAPA} / \mathrm{ri} / \mathrm{Pages} / \mathrm{PlanningReserveMargin.aspx}$

Newell PT, Sotirelis T, Liou K, Meng CI, Rich FJ (2007) A nearly universal solar wind-magnetosphere coupling function inferred from 10 magnetospheric state variables. J Geophys Res. https:// doi.org/10.1029/2006JA012015

Ngwira CM, Pulkkinen AA, Bernabeu E, Eichner J, Viljanen A, Crowley $\mathrm{G}$ (2015) Characteristics of extreme geoelectric fields and their possible causes: localized peak enhancements. Geophys Res Lett 42(17):6916-6921. https://doi.org/10.1002/2015GL065061

Ngwira CM, Sibeck D, Silveira MVD, Georgiou M, Weygand JM, Nishimura Y, Hampton D (2018) A study of intense local dB/ dt variations during two geomagnetic storms. Space Weather 16(6):676-693. https://doi.org/10.1029/2018SW001911 
NRECA (2016) Guide to reducing animal-caused outage, section 4. Tech. rep, National Rural Electric Cooperative Association, pp $27-46$

Office of Cybersecurity Energy Security \& Emergency Response (2020) Electric Disturbance Events (OE-417) Annual Summaries. https:// www.oe.netl.doe.gov/OE417_annual_summary.aspx

Ouyang W, Lawson K, Feng D, Ye L, Zhang C, Shen C (2021) Continental-scale streamflow modeling of basins with reservoirs: towards a coherent deep-learning-based strategy. arXiv:210104423https:// arxiv.org/abs/2101.04423

Pirjola R (2000) Geomagnetically induced currents during magnetic storms. IEEE Trans Plasma Sci 28(6):1867-1873

Polat Ö, Yumak K, Atilla NE, Bağriyanik M (2016) An overview of bird related issues in electrical power systems. IOP Conf Ser 161:012091. https://doi.org/10.1088/1757-899X/161/1/012091

Raoufi H, Vahidinasab V, Mehran K (2020) Power systems resilience metrics: a comprehensive review of challenges and outlook. Sustainability 12(22):9698. https://doi.org/10.3390/su12229698

Rinaldi S, Peerenboom J, Kelly T (2002) Identifying, understanding, and analyzing critical infrastructure interdependencies. IEEE Control Syst 21:11-25. https://doi.org/10.1109/37.969131

Roege P, Collier Z, Mancillas J, McDonagh J, Linkov I (2014) Metrics for energy resilience. Energy Policy 72:249-256. https://doi.org/ 10.1016/j.enpol.2014.04.012

Rosenberg KV, Dokter AM, Blancher PJ, Sauer JR, Smith AC, Smith PA, Stanton JC, Panjabi A, Helft L, Parr M, Marra PP (2019) Decline of the North American avifauna. Science 366(6461):120-124

Sauer JR, Pardieck KL, Ziolkowski DJ, Smith AC, Hudson MAR, Rodriguez V, Berlanga H, Niven DK, Link WA (2017) The first 50 years of the North American Breeding Bird Survey. Condor 119(3):576593. https://doi.org/10.1650/CONDOR-17-83.1

Schrijver CJ, Kauristie K, Aylward AD, Denardini CM, Gibson SE, Glover A, Gopalswamy N, Grande M, Hapgood M, Heynderickx D, Jakowski N, Kalegaev VV, Lapenta G, Linker JA, Liu S, Mandrini CH, Mann IR, Nagatsuma T, Nandy D, Obara T, Paul O'Brien T, Onsager T, Opgenoorth HJ, Terkildsen M, Valladares CE, Vilmer N (2015) Understanding space weather to shield society: a global road map for 2015-2025 commissioned by COSPAR and ILWS. Adv Space Res 55(12):2745-2807. https://doi.org/10. 1016/j.asr.2015.03.023

Scott CA (2013) Electricity for groundwater use: constraints and opportunities for adaptive response to climate change. Environ Res Lett 8(3):035005

Shrestha R, Kumar S, Martin S, Urmee T (2005) Application of productive uses of renewable energy for small medium and micro-enterprises

Siddiqi A, Wescoat JL Jr (2013) Energy use in large-scale irrigated agriculture in the Punjab province of Pakistan. Water Int 38(5):571-586

Sims CA (1980) Macroeconomics and reality. Econometrica 48(1):1-48

Sperstad IB, Kjølle G, Gjerde O (2019) A comprehensive framework for vulnerability analysis of extraordinary events in power systems. Reliab Eng Syst Saf 196:106788. https://doi.org/10.1016/j.ress. 2019.106788

Stankovic A (2018) The definition and quantification of resilience. IEEE PES Industry Technical Support Task Force: Piscataway, NJ, USA https://resourcecenter.ieee-pes.org/publications/technical-reports/ PESTR0065_04-18.html

Strimas-Mackey M, Hochachka WM, Ruiz-Gutierrez V, Robinson OJ, Miller ET, Auer T, Kelling S, Fink D, Johnston A (2020) Best practices for using eBird data. Version 1.0. Cornell Lab of Ornithology, Ithaca, New York, https://cornelllabofornithology.github. io/ebird-best-practices/
Subcommittee D (2012) IEEE guide for electric power distribution reliability indices. IEEE Std 1366-2012 (Revision of IEEE Std 13662003) pp 1-43. https://doi.org/10.1109/IEEESTD.2012.6209381

Sugiura M, Kertz W, Price A, Stone D (1964) Hourly values of equatorial Dst for the IGY. Annals of the International Geophysical Year, Pergamon Press, https://books.google.com/books?id=YtxwN AAACAAJ

Sun AY, Green R, Swenson S, Rodell M (2012) Toward calibration of regional groundwater models using GRACE data. J Hydrol 422 423:1-9. https://doi.org/10.1016/j.jhydrol.2011.10.025

Svoboda M, Fuchs B (2016) Handbook of drought indicators and indices. Integrated Drought Management Programme (IDMP), integrated drought management tools and guidelines series 2. World Meteorological Organization (WMO) and Global Water Partnership (GWP), Geneva

Tsay RS (2013) Multivariate time series analysis: with R and financial applications. Wiley, New York

Uría-Martínez R, Johnson MM, Shan R (2021) U.S. hydropower market report 2021. Tech. rep., U.S. Department of Energy, https://www. energy.gov/sites/prod/files/2021/01/f82/us-hydropower-marketreport-2021_0.pdf

US Department of Energy (2020) Electricity explained: electricity in the United States. Tech. rep

US Energy Information Administration (2019) Annual Electric Power Industry Report, Form EIA-861 detailed data files. https://www. eia.gov/electricity/data/eia861/

US Energy Information Administration (2020) Degree-days. https:// www.eia.gov/energyexplained/units-and-calculators/degree-days. php

US Energy Information Administration (2021) Monthly Energy Review, March 2021. https://www.eia.gov/totalenergy/data/monthly/index. php\#environment

Voisin N, Kintner-Meyer M, Skaggs R, Nguyen T, Wu D, Dirks J, Xie Y, Hejazi M (2016) Vulnerability of the US western electric grid to hydro-climatological conditions: how bad can it get? Energy 115:1-12

Voropai N (2020) Electric power system transformations: a review of main prospects and challenges. Energies 13(21):5639. https://doi. org/10.3390/en13215639

Wanik D, Parent J, Anagnostou E, Hartman B (2017) Using vegetation management and LiDAR-derived tree height data to improve outage predictions for electric utilities. Electr Power Syst Res 146:236-245

WB (2021) The World Bank (WB): Electricity production from hydroelectric sources (\% of total). https://data.worldbank.org/indicator/ EG.ELC.HYRO.ZS

Wolfgang O, Haugstad A, Mo B, Gjelsvik A, Wangensteen I, Doorman G (2009) Hydro reservoir handling in Norway before and after deregulation. Energy 34(10):1642-1651. https://doi.org/10.1016/j. energy.2009.07.025

Xie P, Chen M, Yang S, Yatagai A, Hayasaka T, Fukushima Y, Liu C (2007) A gauge-based analysis of daily precipitation over East Asia. J Hydrometeorol 8(3):607-626. https://doi.org/10.1175/ JHM583.1

Zablocki A (2019) Fact sheet: energy storage 2019 https://www.eesi. org/papers/view/energy-storage-2019

Zambon RC, Barros MTL, Yeh WWG (2016) Impacts of the 20122015 Drought on the Brazilian Hydropower System, pp 82-91. https://doi.org/10.1061/9780784479858.010

Zio E (2016) Challenges in the vulnerability and risk analysis of critical infrastructures. Reliab Eng Syst Saf 152:137-150. https://doi. org/10.1016/j.ress.2016.02.009 